\title{
Comprehensive Review on Effective Strategies and Key Factors for High- Performance Piezoelectric Energy Harvester at Low Frequency
}

\author{
N. H. H. A. Talib ${ }^{1 *}$, H. Salleh ${ }^{1}$, B. D. Youn ${ }^{2}$ and M. S. M. Resali ${ }^{1}$ \\ ${ }^{1}$ Institute of Sustainable Energy, Universiti Tenaga Nasional, 43000 Kajang, Selangor. \\ *Email: n.fizahani@gmail.com \\ ${ }^{2}$ Department of Mechanical Aerospace Engineering, Seoul National University, 08826 \\ Seoul, South Korea
}

\begin{abstract}
In the past decade, there has been rapid development in piezoelectric energy harvester due to its limited application and low output power. This paper critically reviews the strategies implemented to improve the power density for low-frequency applications. These strategies include piezoelectric material selection as well as optimisations of shape, size and structure. The review also focuses on the recent advances in multi-modal, nonlinear and multi-directional energy harvesting. Based on the comprehensive summary of the normalised power density at $1 \mathrm{~g}$ acceleration, it was found that most works fell in the second quadrant of low frequency and high power density. The maximum value was around $1 \mathrm{~mW} / \mathrm{mm}^{3} / \mathrm{g}$. Adding an extension of beam or spring to the conventional piezoelectric beam could enhance the normalised power density dramatically. Additionally, the multi-modal energy harvester exhibits broader bandwidth when its multiple resonance peaks get closer. The findings indicate that the anticipated performance of a piezoelectric harvester can be attained by achieving the trade-off between output power and bandwidth. To achieve high performance at low frequency, the following factors are essential: excellent material characteristics optimised geometry for high strain energy density, excellent flexibility, high excitation amplitude and broad bandwidth.
\end{abstract}

Keywords: Piezoelectric energy harvester; low frequency; renewable energy; vibration.

\section{INTRODUCTION}

Ambient energy was no longer overlooked as a viable energy source as methods have been developed to harvest energy from heat and vibration sources since many decades ago. Due to the popularity of smaller electronics applications and the increasing demand for maximising the lifespan of batteries, many researchers have been looking into the potential of vibration-based power generators. Electrical energy can be converted from kinetic energy by using piezoelectric material which generates an electrical signal when it encounters vibration (mechanical strain). The energy density of a typical piezoelectric energy harvester is at least three times larger than those of electromagnetic and electrostatic transducers [1]. Applications of piezoelectric energy harvester include a wireless medical implant that harvests energy from heartbeat to power the modern cardiac pacemaker [2], embedded sensors in buildings [3,4], transportations [5,6] and wearable [7-9] or handheld devices such as self-charging mobile phone [10]. The current research trend is the developments of micro [11] and nano power generators [12,13]. However, the main drawback of harvesting energy from piezoelectric material is low output power as 
they allow vibration scavenging for a specific frequency only. Furthermore, energy is particularly most abundant at the low-frequency range. However, the low-frequency vibration sources usually have low amplitudes, for example in human motions $[14,15]$. Therefore, many strategies have been implemented to improve the performance of piezoelectric energy harvester at low frequency. This paper systematically reviews the works conducted, aiming to identify the effective strategies and key factors for high power density (the amount of output power per unit piezoelectric volume). The targeted frequency range is below $200 \mathrm{~Hz}$. The findings benefit the low-frequency applications, including but not limited to self-powered wireless sensors for health and condition monitoring such as on railway tracks [16], bridges [17] and rotating machines [18].

\section{SELECTION OF PIEZOELECTRIC MATERIAL}

\section{Characteristics of Piezoelectric Materials}

The characteristics of piezoelectric materials are determined by a set of parameters: Strain coefficient, voltage constant, dielectric constant, electromechanical coupling factor, mechanical quality factor and Curie temperature [19]. Strain coefficient is the ratio of mechanical displacement per unit electrical field applied or the ratio of short circuit charge density per unit mechanical stress applied. Voltage constant gives the amount of mechanical strain experienced by material per unit charge density applied or the value of open-circuit electrical field generated per unit mechanical stress applied. High dielectric constant shows a high amount of charge that can be stored in the piezoelectric material, hence, a higher output power of a harvester. Electromechanical coupling factor indicates the effectiveness of mechanical to electrical energy conversion and vice versa. It is defined as the square root of electrical (mechanical) energy stored per unit mechanical (electrical) energy applied. These important parameters should be considered when selecting piezoelectric material. The material of high energy density generally has a high product of strain coefficient and voltage constant. Material with higher dielectric constant and electromechanical coupling factor has a better capacitive characteristic and energy conversion efficiency, respectively. Higher quality factor indicates lower energy losses. Precaution should be taken against Curie temperature as a material would lose its piezoelectric effect. It is advisable to restrict the working temperature to half of the limit.

\section{Piezoelectric Materials for Low-Frequency Applications}

The widely used synthetic piezoelectric material such as PZT is an established material and commercially available for researchers. Conventional energy harvester employs a cantilever beam structure. To attain a low natural frequency, beam with low stiffness and high effective tip mass is normally employed. The latter is mainly contributed by partial beam mass and attached external mass. PZT is a high-density material of ca. $7600 \mathrm{kgm}^{-3}$ and its elastic modulus are generally above 50GPa. Although the performance of PZT is broadly acknowledged, researchers have been developing new materials with better properties for low-frequency application. PVDF polymer and PZN-PT single crystal have been regarded as having the highest values of piezoelectric voltage constant and energy density, respectively [20]. Their low elastic moduli (ca. $6.9 \mathrm{GPa}$ and ca. $22.93 \mathrm{GPa}$, respectively) are advantageous for low-frequency energy harvesting [21,22]. However, PVDF is a low-density material and has a low electromechanical coupling factor (ca. 0.16 ). On the other hand, PZN-PT has a favourable density of $8333 \mathrm{kgm}^{-3}$ and an excellent 
electromechanical coupling factor of approximately 0.877 . But, mass production of both materials is not feasible as they are expensive. Another novel single crystal material is PMN-PT, where it possesses a low modulus of elasticity (19.8GPa). In fact, Yang et al. [23] showed that PMN-PT outperformed PZT in terms of electromechanical properties. Previously, Kim et al. [24] reported that PMN-PT generated more voltage than PZT-5H. At $109.06 \mathrm{~Hz}$, the topologically optimised beam of PMN-PT generated $6.74 \mathrm{~V}$ whereas PZT produced $30.27 \%$ less voltage at higher frequency (10.35\% higher). PMN-PT also performed better than MFC and PVDF that produced merely $4.36 \mathrm{~V}$ at $111.07 \mathrm{~Hz}$ and $3.55 \mathrm{~V}$ at $95.0 \mathrm{~Hz}$, respectively. To address the issue of low Curie point, a modified PMNPT known as PIN-PMN-PT has been developed. Luo et al. [25] have successfully grown the PIN-PMN-PT crystal that table maintained the outstanding piezoelectric properties of PMN-PT crystal with the possibility to operate at a temperature of $30-40{ }^{\circ} \mathrm{C}$ higher. Zhang et al. [26] reported similarly where the electromechanical coupling and strain coefficient were maintained at $90 \%$ and $1500 \mathrm{pC} / \mathrm{N}$, respectively, at higher operating temperature. The dielectric properties of PIN-PMN-PT also exhibited minimum dependency on thickness whereas the permittivity of PMN-PT halved at a thickness of $40 \mu \mathrm{m}$. DeAngelis et al. [27] agreed that PIN-PMN-PT surpassed the performance of PZT where the volume of material could be minimized for the same impedance. To be a good substitute for PZT, there is a need for adequate design guidelines to explore this material further. The parameters of the discussed piezoelectric materials are listed in Table 1.

Table 1. Parameters of common piezoelectric materials.

\begin{tabular}{|c|c|c|c|c|c|c|c|c|c|c|}
\hline \multirow[t]{2}{*}{ Material } & \multicolumn{3}{|c|}{$\begin{array}{l}\text { Charge constant }\left(10^{-}\right. \\
12 \mathrm{~m} / \mathrm{V})\end{array}$} & \multicolumn{3}{|c|}{$\begin{array}{c}\text { Voltage constant }\left(10^{-}\right. \\
\left.{ }^{3} \mathrm{Vm} / \mathrm{N}\right)\end{array}$} & \multirow{2}{*}{$\begin{array}{l}\text { Mech. } \\
\text { quality } \\
\text { factor }\end{array}$} & \multirow{2}{*}{$\begin{array}{l}\text { Curie } \\
\text { point } \\
\left({ }^{\circ} \mathrm{C}\right)\end{array}$} & \multirow{2}{*}{$\begin{array}{l}\text { Density } \\
\left(\mathrm{kg} / \mathrm{m}^{3}\right)\end{array}$} & \multirow[t]{2}{*}{ Ref. } \\
\hline & $\mathrm{d}_{33}$ & $\mathrm{~d}_{31}$ & $\mathrm{~d}_{15}$ & $\mathrm{~g}_{33}$ & $\mathrm{~g}_{31}$ & $\mathrm{~g}_{15}$ & & & & \\
\hline PZT-2 & 152 & -60.2 & 440 & 38.1 & -15.1 & 50.3 & 680 & 370 & 7600 & [28] \\
\hline PZT-4 & 289 & -123 & 496 & 26.1 & -11.1 & 39.4 & 500 & 328 & 7500 & [28] \\
\hline PZT-5A & 374 & -171 & 584 & 24.8 & -11.4 & 38.2 & 75 & 365 & 7750 & [28] \\
\hline PZT-5H & 593 & -274 & 741 & 19.7 & -9.1 & 26.8 & 65 & 193 & 7500 & [28] \\
\hline PZT-8 & 225 & -37 & 330 & 25.4 & -10.9 & 28.9 & 1000 & 300 & 7600 & [28] \\
\hline PZT-6A1 & 189 & -80 & & 20.4 & -8.5 & & 450 & 335 & 7450 & [29] \\
\hline PZT-6A2 & 151 & -59.5 & & 19.2 & -7.5 & & 550 & 335 & 7450 & [29] \\
\hline PZT-6B & 71 & -27 & 130 & 18.0 & -6.85 & 30.8 & 1300 & 350 & 7550 & [29] \\
\hline PZT-7A & 150 & -60 & 362 & 39.9 & -15.9 & 48.8 & 600 & 350 & 7600 & [29] \\
\hline $\begin{array}{l}\text { PMT-PT- } \\
0.03 \mathrm{Bi}\end{array}$ & 310 & & & & & & & 200 & 7900 & [30] \\
\hline PMN-PT & 4000 & & & & & & 100 & 130 & & [30] \\
\hline $\begin{array}{l}\text { PIN24- } \\
\text { PMN-PT }\end{array}$ & 2200 & & & 39 & & & 123 & 135 & 8150 & [27] \\
\hline $\begin{array}{l}\text { PIN36- } \\
\text { PMN-PT }\end{array}$ & 3750 & & & & & & 800 & 175 & & [26] \\
\hline $\mathrm{BaTiO}_{3}$ & 145 & -58 & 245 & 13.1 & -5.2 & 20.5 & 300 & 120 & & [31] \\
\hline $\begin{array}{l}\text { Modified } \\
\mathrm{BaTiO}_{3}\end{array}$ & 149 & -58 & 242 & 14.1 & -5.5 & 21 & 400 & 115 & 5550 & [32] \\
\hline BT-CT-Co & 150 & & & 12 & & & 800 & 109 & & [33] \\
\hline KNN (HP) & 127 & & & 29 & & & 240 & 420 & & [33] \\
\hline $\mathrm{KNN}-\mathrm{Cu}$ & 86 & & & 42 & & & 2280 & 414 & & [33] \\
\hline KNN-KCT & 90 & & & 40 & & & 1300 & 385 & & [33] \\
\hline KNN-LS & 265 & -114 & 340 & 20 & & & 40 & 368 & 4550 & [31] \\
\hline KNN-LT & 230 & & & 21 & & & 73 & 323 & & [33] \\
\hline $\begin{array}{l}\text { KNN-LS- } \\
\text { CT(1\%) }\end{array}$ & 210 & -87 & 268 & & & & & 330 & 4550 & [31] \\
\hline
\end{tabular}




\begin{tabular}{l|ccc|c|ccc|c} 
KNN-LS- & 180 & -68 & 232 & & & 296 & 4550 & {$[31]$} \\
CT(2\%) & 135 & & & 24 & 110 & 280 & & {$[33]$} \\
BNBK79 & 135 & & 150 & 262 & & {$[33]$} \\
BNBK88 & 170 & & & 24 & & 205 & 1780 & {$[40,34]$} \\
PVDF & -33 & 23 & & -339 & & 80 & & {$[35]$} \\
MFC & 440 & -185 & 560 & & & 464 & 4250 & {$[36]$} \\
NKLN- & 258 & & & & & 561 & & {$[37]$} \\
CT(0.5\%) & 18 & & & & 110 & 302 & & {$[38]$} \\
SNSBT & 18 & & & & 200 & 5600 & {$[39,40]$} \\
NBT-KBT- & 145 & & & & & & & \\
BT & 120 & -40 & 110 & & & & & \\
PIC 700 & 120 & & & & & & & \\
\hline
\end{tabular}

Table 1 cont. Parameters of common piezoelectric materials.

\begin{tabular}{|c|c|c|c|c|c|c|c|c|c|c|}
\hline \multirow{2}{*}{ Material } & \multicolumn{4}{|c|}{ Relative dielectric constant } & \multicolumn{5}{|c|}{ Electromechanical coupling factor } & \multirow{2}{*}{ Ref. } \\
\hline & $\mathrm{K}_{33}^{\mathrm{T}}$ & $\mathrm{K}_{33}^{\mathrm{S}_{3}}$ & $\mathrm{~K}^{\mathrm{T}} 11$ & $\mathrm{~K}^{\mathrm{S}}{ }_{11}$ & $\mathrm{k}_{33}$ & $\mathrm{k}_{31}$ & $\mathrm{k}_{15}$ & $\mathrm{k}_{\mathrm{p}}$ & $\mathrm{k}_{\mathrm{t}}$ & \\
\hline PZT-2 & 450 & 260 & 990 & 504 & 0.626 & -0.28 & 0.701 & -0.47 & 0.508 & [28] \\
\hline PZT-4 & 1300 & 635 & 1475 & 730 & 0.7 & -0.334 & 0.71 & -0.58 & 0.513 & [28] \\
\hline PZT-5A & 1700 & 830 & 1730 & 916 & 0.705 & -0.334 & 0.685 & -0.60 & 0.486 & [28] \\
\hline PZT-5H & 3400 & 1470 & 3130 & 1700 & 0.752 & -0.388 & 0.675 & -0.65 & 0.505 & [28] \\
\hline PZT-8 & 1000 & 600 & 1290 & 900 & 0.64 & -0.30 & 0.55 & -0.51 & 0.48 & [28] \\
\hline PZT-6A1 & 1050 & 730 & & & 0.54 & -0.248 & & 0.42 & 0.39 & [29] \\
\hline PZT-6A2 & 890 & 680 & & & 0.47 & -0.207 & & 0.35 & 0.35 & [29] \\
\hline PZT-6B & 460 & 386 & 475 & 407 & 0.375 & -0.145 & 0.377 & 0.25 & 0.302 & [29] \\
\hline PZT-7A & 425 & 235 & 840 & 460 & 0.66 & -0.30 & 0.67 & 0.51 & 0.50 & [29] \\
\hline PMT-PT-0.03Bi & 6600 & & & & & & & 0.42 & & [30] \\
\hline PMN-PT & 5833 & 750 & & & 0.93 & & & & & [30] \\
\hline PIN24-PMN-PT & 5325 & & & & 0.92 & -0.676 & & & & [27] \\
\hline PIN36-PMN-PT & 5625 & 833 & & & 0.92 & & & & & [26] \\
\hline $\mathrm{BaTiO}_{3}$ & 1700 & & & & 0.50 & & & & & [31] \\
\hline Modified $\mathrm{BaTiO}_{3}$ & 1200 & 910 & 1300 & 1000 & 0.48 & -0.194 & 0.48 & -0.33 & 0.384 & [32] \\
\hline BT-CT-Co & 1420 & & & & 0.46 & & & & & [33] \\
\hline KNN (HP) & 496 & & & & 0.61 & & & & & [33] \\
\hline $\mathrm{KNN}-\mathrm{Cu}$ & 231 & & & & & & & 0.38 & & [33] \\
\hline KNN-KCT & 250 & & & & & & & 0.42 & & [33] \\
\hline KNN-LS & 1380 & & 1200 & & 0.62 & -0.30 & 0.57 & -0.50 & 0.46 & [31] \\
\hline KNN-LT & 1256 & & & & & & & 0.51 & & [33] \\
\hline KNN-LS-CT(1\%) & 1170 & & 1120 & & 0.61 & -0.29 & 0.56 & -0.49 & 0.43 & [31] \\
\hline KNN-LS-CT(2\%) & 1022 & & 1100 & & 0.56 & -0.25 & 0.5 & -0.42 & 0.41 & [31] \\
\hline BNBK79 & 650 & & & & 0.54 & & & & & [33] \\
\hline BNBK88 & 810 & & & & 0.60 & & & & & [33] \\
\hline PVDF & 12 & & & & 0.16 & & & & & {$[40,34]$} \\
\hline MFC & 1850 & & 1950 & & & & & & & [35] \\
\hline NKLN-CT $(0.5 \%)$ & 1014 & & & & & & & & & {$[36]$} \\
\hline SNSBT & 1400 & & & & & & & 0.59 & & [37] \\
\hline NBT-KBT-BT & 820 & & & & 0.519 & & & 0.162 & & [38] \\
\hline PIC 700 & 700 & & 570 & & 0.4 & 0.14 & 0.3 & 0.15 & 0.4 & {$[39,40]$} \\
\hline
\end{tabular}

Apart from developing new materials, ways to improve the flexibility of PZT thin films such as those of using thermoplastic as a substrate [41-43] or as an encapsulation [44] have been proposed. Qi et al. [45] demonstrated the effectiveness of integrating piezoelectric materials with rubber for flexibility. Inspired by this innovation, Muhamad and Salleh $[46,47]$ employed natural rubber in the form of latex to coat the commonly used PZT bimorph and revealed that its natural frequency decreased with the number of the coating layer. These findings promoted the role of rubber in increasing the elasticity of PZT-based energy harvester. Japan-based Ricoh Co. [48] developed new rubber-based 
energy-generating material. The output power was on par with that of piezoceramics and meanwhile, it exhibited superior flexibility. While research is still ongoing, this new material could improve the wearable and handheld energy harvesters.

\section{OPTIMISATION OF MATERIAL GEOMETRY}

\section{Optimum Shape and Size}

Traditionally, the piezoelectric material is bonded on a substrate and built in the form of a rectangular cantilever beam. However, utilising more piezoelectric material does not guarantee the efficiency of a harvester. Mineto et al. [49] identified the highest output power of $6500 \mu \mathrm{W}$ was obtained when PZT covered approximately half of the substrate. Meanwhile, many studies [50-55] discussed the possibility to improve output power by modifying the geometry of the conventional rectangular beam to a trapezoidal and triangular shape. Benasciutti et al. [56] found that the output power was dependent on piezoelectric's surface area, particularly the width. With sinusoidal excitation of $2 \mathrm{~ms}^{-2}$ at $50 \mathrm{~Hz}$, both trapezoidal and reversed trapezoidal beams have greater power density by $24 \%$ and $113 \%$, respectively when compared to a rectangular beam. Hosseini and Hamedi [57] reported that the natural frequency of trapezoidal cantilever decreased with increased length. However, this trend was only valid until the length of 70-80 mm. Beyond this point, the frequency increased unless the width increased. Kherbeet et al. [58] compared the stress-strain distribution of rectangle, trapezoidal and triangle cantilevers (see Figure 1). The triangular beam produced $4.876 \mathrm{~mW}$ at $85 \mathrm{~Hz}$. Whereas trapezoidal and rectangular beams produced $3.25 \mathrm{~mW}$ and $1.05 \mathrm{~mW}$, respectively. Their results were consistent with the data obtained by Siddiqui et al. [59]. They verified that the deflection and internal strain energy per unit area of the triangular beam was much greater than the rectangular beam. This finding was pretty much agreed by Su et al. [60] but they also anticipated the challenge in mounting a triangular beam. Hence, a perforated rectangular piezoelectric beam was proposed. The stress of the cantilever increased as the centreline hole was made farther from the free end. However, when the hole was too close to the fixed end, the extreme concentrated stress around it caused the piezoelectric beam to entirely break. Reddy et al. [61] on the other hand studied a rectangular beam with a trapezoidal cavity with different taper angles $(\alpha)$ as illustrated in Figure 2. There was a favourable trend in which the natural frequency reduces, and the output voltage increases as $\alpha$ increases. But several questions remain unanswered at the present such as optimisations of cavity size and location. Further studies addressing these issues should be undertaken. Figure 3 illustrates an inversed S-shaped beam developed by Mehdipour and Braghin [62]. The proposed beam aimed to interrupt the decreasing trend of bonding area of the piezoelectric layer and in turn maximize the resulting electric potential along with the upper layer. The proposed beam was more flexible than the straight beam and produced a slightly higher voltage at $100 \mathrm{~Hz}$. This new shape performed better in terms of the required excitation force; however, its workability in physical testing remained questionable.

Based on the reported findings, the advantages and disadvantages of the piezoelectric beam shapes are presented in Table 2. It is important to note that each of the beam shapes is compared with its respective benchmark. 


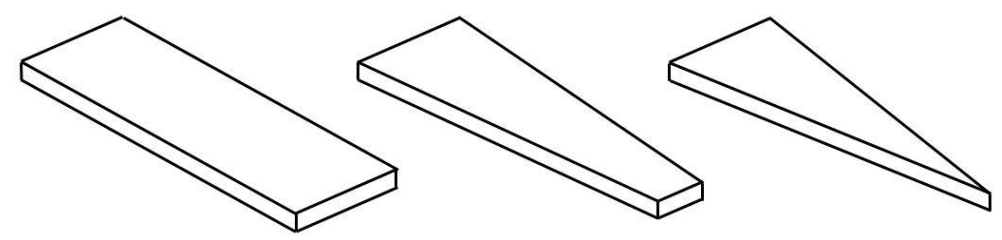

Figure 1. Schematic diagram of beam geometries investigated by Kherbeet et al. [58].

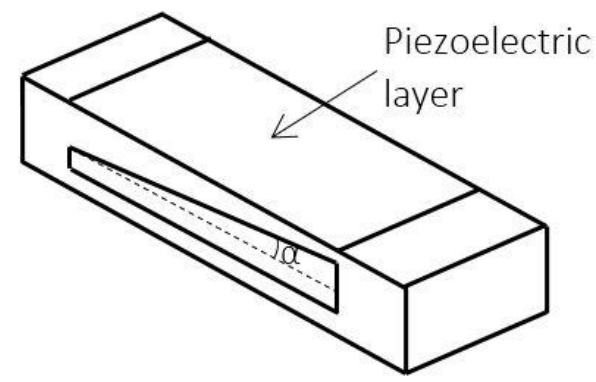

Figure 2. Schematic diagram of a rectangular beam with a trapezoidal cavity proposed by Reddy et al. [61].

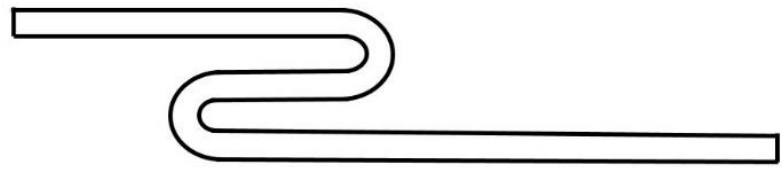

Figure 3. Schematic diagram of inverted S-shaped beam proposed by Mehdipour and Braghin [62].

\section{Optimum Multi-Layer Structure}

The number of the piezoelectric layer and electrode connection type influence the performance of an energy harvester. This subject was first explored by Song et al. [63] in 2009. The study revealed that the output voltage suffered a significant drop (in contrast to the output current) as the number of layers connected in parallel increased. However, the largest output power was still produced by single layer harvester. In 2010, Zhu et al. [64] reported a contradicting finding in which a multi-layer bimorph harvester produced more output power at the same total thickness and frequency. In fact, the researchers argued that the previous study was not theoretically supported. Double layer harvester produced $41.51 \%$ higher output power than single layer when harmonically excited at $0.41 \mathrm{~g}$. However, the output power declined for triple layer harvester. Hence, the fabrication of triple or more layer harvester was not recommended.

Further investigation concluded that multi-layer structure improved the output power regardless how PZT layers were connected [65]. However, higher output power was recorded for series connected harvester and it increased with the number of PZT layers. A maximum of $458.66 \mu \mathrm{W}$ was recorded for series connected triple layer. After many years, the findings reported by Song et al. [63] was validated by Jemai et al. [66]. While the previous experimental results demonstrated a small reduction of output power ca. $15 \%$ as the number of layers was increased, current analysis showed the insignificance of this parameter change against the output power. A possible explanation for this 
discrepancy might be the increase in electrode thickness whenever a new layer was introduced in the experiment. Thus, the piezoelectric material volume had to be sacrificed to maintain the total thickness. But the theoretical analysis omitted the influence of electrode thickness, leaving the material volume unaffected. Shin et al. [67] investigated a non-cantilevered multi-storey energy harvester based on PZT multi-layer actuators connected in parallel. The average output power increased with the number of storeys at a constant applied force, achieving a maximum value of $1.25 \mathrm{~mW}$. The increase in output power was expected as more piezoelectric materials were used. However, the declining trend of power density should be addressed in future investigation.

Table 2. Comparison of piezoelectric beam shapes with respective benchmarks.

\begin{tabular}{|c|c|c|c|}
\hline Beam shapes & Benchmark & Advantages & Disadvantages \\
\hline $\begin{array}{l}\text { Rectangular } \\
\text { beam. }\end{array}$ & $\begin{array}{l}\text { - Trapeziodal beam } \\
\text { - Triangular beam }\end{array}$ & $\begin{array}{l}\text { - Most practical and widely } \\
\text { available. } \\
\text { - Easily incorporated with } \\
\text { overall structure }\end{array}$ & $\begin{array}{l}\text { - Lowest internal strain } \\
\text { energy } \\
\text { - Lowest output power } \\
\text { - Most piezo consumption }\end{array}$ \\
\hline $\begin{array}{l}\text { Trapezoidal } \\
\text { beam }\end{array}$ & - Rectangular beam & $\begin{array}{l}\text { - Higher internal strain } \\
\text { energy } \\
\text { - Higher output power } \\
\text { - Less piezo consumption }\end{array}$ & $\begin{array}{l}\text { - Not readily available } \\
\text { - Risk for piezo crack or } \\
\text { breakage during cutting }\end{array}$ \\
\hline $\begin{array}{l}\text { Triangular } \\
\text { beam }\end{array}$ & $\begin{array}{l}\text { - Rectangular beam } \\
\text { - Trapezoidal beal }\end{array}$ & $\begin{array}{l}\text { - Highest internal strain } \\
\text { energy } \\
\text { - Highest output power } \\
\text { - Least piezo consumption }\end{array}$ & $\begin{array}{l}\text { - Not readily available } \\
\text { - Risk for crack or breakage } \\
\text { during cutting }\end{array}$ \\
\hline $\begin{array}{l}\text { Perforated } \\
\text { rectangular } \\
\text { beam }\end{array}$ & $\begin{array}{l}\text { - Unpunched } \\
\text { rectangular beam }\end{array}$ & $\begin{array}{l}\text { - Higher internal strain } \\
\text { energy } \\
\text { - Higher output power }\end{array}$ & $\begin{array}{l}\text { - Risk of piezo crack or } \\
\text { breakage due to extreme } \\
\text { concentrated stress }\end{array}$ \\
\hline $\begin{array}{l}\text { Inverted S- } \\
\text { shaped beam }\end{array}$ & - Rectangular beam & $\begin{array}{l}\text { - Higher output power } \\
\text { - More flexible }\end{array}$ & $\begin{array}{l}\text { - Not readily available } \\
\text { - Risk for piezo crack or } \\
\text { breakage due to the } \\
\text { complicated shape } \\
\text { - More piezo consumption } \\
\text { due to higher total beam } \\
\text { length. }\end{array}$ \\
\hline
\end{tabular}

\section{MULTI-MODAL ENERGY HARVESTING}

An energy harvester with multiple vibrational modes can undergo resonance at a broader frequency range and therefore it is more capable of producing a higher output power. This is termed as multi-modal energy harvesting and usually benefits from a multi-degree of freedom structure or an array of cantilevers. However, several researchers have reported that it can also be realized by segmenting the piezoelectric layer. The studies reveal that the segmented layer has an advantage over the continuous layer in which it allows the higher vibration modes to be simultaneously excited.

\section{Multi-Degree of Freedom Configuration}

Coupling the beam can form a multi-degree of freedom (DOF) structure that has multiple resonance peaks. The simplest arrangement is a 2-DOF system. Lam and Salleh $[68,69]$ connected the piezoelectric cantilever to the base via an external slotted aluminium beam 
and recorded $56 \mathrm{~mW}$ at $30 \mathrm{~Hz}$. Hong et al. [70] harvested a maximum of $7.8 \mathrm{~mW}$ at 69 $\mathrm{Hz}$ by attaching additional springs at the free end of the piezoelectric cantilever beam. Although, the existence of a second peak had not been reported by both studies. Erturk et al. [71] suggested an L-shaped energy harvester that produced two resonance peaks with the highest amounted to $10 \mathrm{~mW}$ per base acceleration in $\mathrm{g}$ at $22.8 \mathrm{~Hz}$ (see Figure 4). The energy harvester had improved bandwidth; however, the exact value was not stated. Notwithstanding this promising theoretical demonstration, there is a concern whether it could perform well in physical condition. Although the researchers mentioned that the experimental validation was under progress, they had not disclosed further details and outcomes. Xu et al. [72] experimented with another right angle coupled beam as shown in Figure 5 that could efficiently smoothen the strain distribution when a torque was introduced. Two resonance peaks were evident with base excitation at $2.5 \mathrm{~ms}^{-2}$. The first peak reached $13.54 \mathrm{~mW}$ at $38.3 \mathrm{~Hz}$, which was $64.72 \%$ more than the power recorded for traditional cantilever. The superior performance of L-shaped energy harvester had also been acknowledged by X. Nie [73] in their recent work.

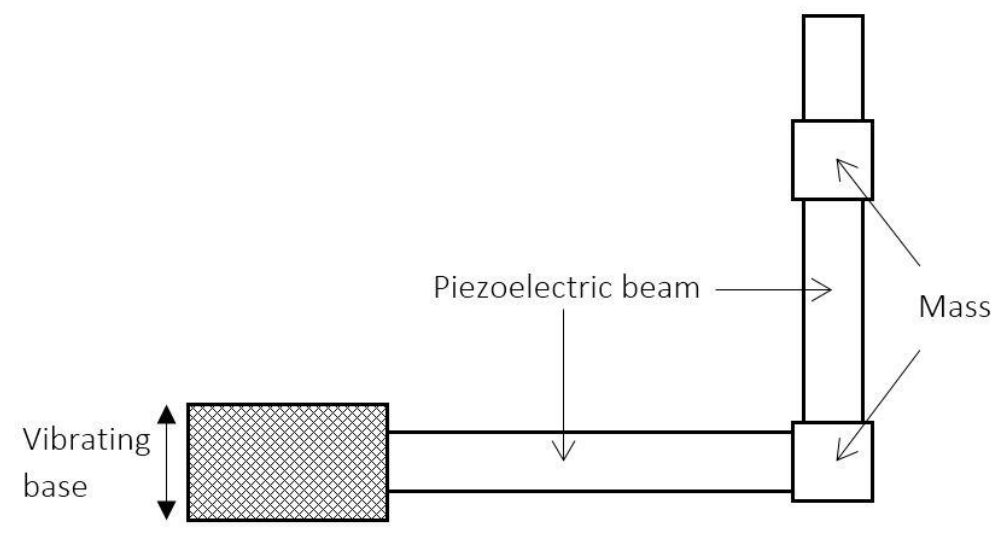

Figure 4. Schematic diagram of L-shaped energy harvester developed by Erturk et al. [71].

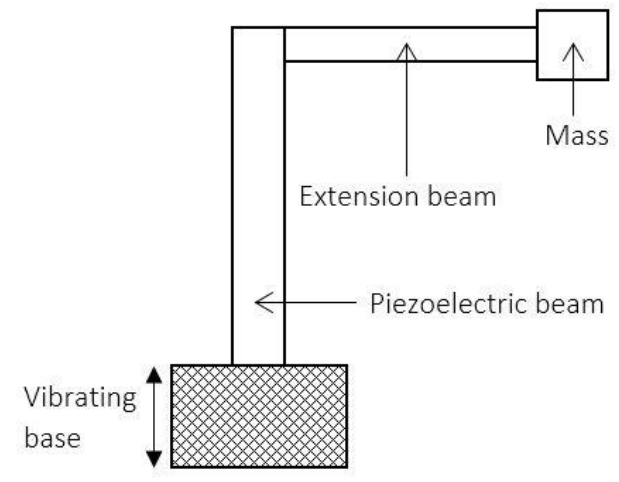

Figure 5. Schematic diagram of right angle coupled energy harvester proposed by Xu et al. [72].

Wang et al. [74] proposed an additional elastic system to amplify the base excitation and induce a closer second peak. The harvester generated two peaks of 67.7 $\mathrm{mW}$ and $9.7 \mathrm{~mW}$ at $78.3 \mathrm{~Hz}$ and $100.3 \mathrm{~Hz}$, respectively, with excitation of $1 \mathrm{~g}$. The numerical investigation indicated that the maximum output power and peak distance 
could be further improved by specifying a smaller mass ratio. It would be interesting to assess the key design parameters experimentally and identify the practical constraints simultaneously. Staaf et al. [75] coupled two parallel-connected PZT bimorph cantilevers. A peak occurred at $85.2 \mathrm{~Hz}$ and the other appeared at $135.5 \mathrm{~Hz}$ which was near the first frequency, suggesting a broadband characteristic. The proposed harvester design outperformed the two parallel uncoupled cantilevers by producing 5.4 times of their output power. The output power and bandwidth could be further enhanced with low damped coupling fixture, but not without compromising the working frequency of the device.

\section{Cantilever Array Configuration}

The cantilever array configuration has been widely explored and a few designs have been granted for patent [76-78]. Xue et al. [79] presented an energy harvester with 10 seriesconnected PZT bimorphs with different thickness. Upon excitation of $1 \mathrm{~ms}^{-2}$, the array produced at least $10 \mu \mathrm{W}$ higher than the maximum output power of single bimorph harvester at $98 \mathrm{~Hz}$. However, the power density of the array reduced by four times. Perhaps the increase in frequency bandwidth from $6 \mathrm{~Hz}$ to $28 \mathrm{~Hz}$ would compensate for the large piezoelectric material usage. Zhang and Afzalul [80] proposed joining 12 bimorphs with spring connected end masses. As the base was excited at $1 \mathrm{~ms}^{-2}$, it improved the output power by $92.31 \%$ to $250 \mu \mathrm{W}$ at $90 \mathrm{~Hz}$ compared to a single harvester and generated the highest amount of $430 \mu \mathrm{W}$ at $99 \mathrm{~Hz}$. Yet, the proposed harvester still had a relatively low power density. Besides, no comparison with conventional piezoelectric array was carried out to analyse the influence of the springs. Dayou et al. $[81,82]$ split a PVDF bender evenly to form an array. The higher the number of splits, the larger the power harvested for the same amount piezoelectric material. The array produced a maximum of $53 \mu \mathrm{W}$ at $27.2 \mathrm{~Hz}$, whereas a single bender only produced $36.23 \%$ of it. However, the excitation level is too high i.e. $2 \mathrm{~mm}$ (nearly $6 \mathrm{~g}$ ). It raises the question of whether the same outcome can be achieved if the excitation is lowered to a practical value. Kherbeet et al. [58] reported that series connected triangular beams harvested more power than single cantilever whether in a horizontal or vertical arrangement. The former generated a maximum of $6.774 \mathrm{~mW}$ at $105 \mathrm{~Hz}$ with four cantilevers while the latter surprisingly produced $12.3 \%$ higher output power with only three cantilevers. However, single cantilever had 54.33\% larger power density. It shows that one would have to achieve a compromise between output power and material usage when proposing for cantilever array configuration.

\section{Segmentation of Piezoelectric Layer}

Segmenting the piezoelectric material layer was known to benefit excitation at higher vibration modes. With an excitation force of $0.01 \mathrm{~N}$, Liu et al. [83] discovered that splitting the length of an aluminium nitride layer to 20 segments resulted in $3.86 \mathrm{~nJ}$ of energy stored at $970 \mathrm{~Hz}$, presumably the second mode (see Figure 6). Compared with the continuous layer configuration, the energy output was almost doubled with a frequency of $13.39 \%$ lower. The stored energy relied on distribution of electrical displacement along the beam. The effect of strain nodes in the continuous layer that caused strong voltage cancellation was explained by De Marqui Jr et al. [84]. The second and higher vibration modes of a piezoelectric beam had certain strain nodes, i.e. positions where the sign of bending strain distribution towards the beam length changed. These modes were excited 
as well due to random vibration source. Therefore, the researchers divided the PZT layer and harvested the voltage produced at the opposite sides of a strain node with different electrode pairs to fix this common issue of fixed-free boundary conditions. A simple demonstration on the first two vibration modes i.e. $7.1 \mathrm{~Hz}$ and $40.8 \mathrm{~Hz}$ showed that the performances of control and segmented energy harvester were comparable for excitation at the first mode, generating $0.3 \mathrm{~V}$. However, the output voltage of segmented harvester increased dramatically at second mode to $2 \mathrm{~V}$, which was more than four times the value of control condition. The approach was also verified by Zizyz et al. [85]. However, the researchers found that segmentation at strain nodes did not always produce the largest output voltage. Thus, the principle to determine the optimum segmentation points were presented.

A new piezoelectric structure which was called the energy harvesting skin was proposed by Lee et al. [86-89]. The skin structure could be directly attached to the vibrating surface without clamping. Therefore, it was expected to be more practical than the cantilever structure. The output power increased as more segmentations were performed to the skin. However, the sensitivity of the skin to boundary conditions such as the tightness of the joint could be regarded as one of the concerns and therefore it should be emphasized in the future work. Moreover, multiple segmentations can increase the layout complexity with crammed electrical wiring. Hence, a more sophisticated wiring method such as conductive tape or silver pen is required to deal with this issue.

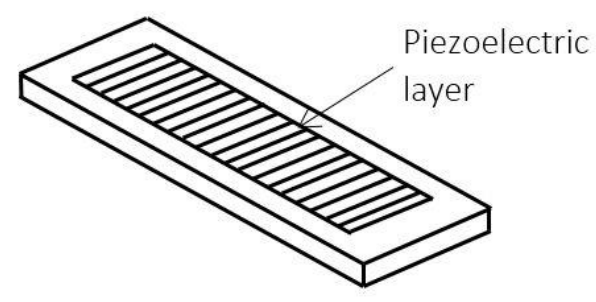

Figure 6. Schematic diagram of 20-segmented piezoelectric layer proposed by Liu et al. [83].

\section{NONLINEAR ENERGY HARVESTING}

In recent years, a large and growing body of literature has explored the potential of nonlinear energy harvesters. Piezoelectric energy harvester can be nonlinear in terms of its stiffness or material coupling [90]. Normally, the former is relatively easier to attain and control as compared to the latter which is dependent on the manufacturing process. Thus, the remaining part of this section proceeds with energy harvesting systems that exploit different types of oscillator to introduce nonlinear stiffness. However, it is important to note that the nonlinear behaviour generally emerges when the energy harvester is subjected to vibration with significant amplitude.

\section{Impact-Enhanced Configuration}

An impact-enhanced configuration employs the nonlinear dynamics of piecewise linear oscillator and commonly associates with the use of a stopper that protects the piezoelectric material from over bending. Ferrari et al. [91] introduced a central stopper in between the top and bottom piezoelectric bimorphs to exert intermittent impact, causing a nonlinear frequency up-conversion mechanism (see Figure 7). Two individual beams produced only 
two voltage peaks of $15 \mathrm{~V}$ and $13 \mathrm{~V}$ at $40 \mathrm{~Hz}$ and $65 \mathrm{~Hz}$, respectively, when harmonically excited at $1 \mathrm{~g}$. With the stopper, multiple peaks occurred at various frequencies between $20-100 \mathrm{~Hz}$. The maximum peak of $13 \mathrm{~V}$ appeared at $20 \mathrm{~Hz}$. This reduction was due to the energy loss when in contact with the stopper. However, the quadratic sum of output voltage was larger over a wider bandwidth. The output power was calculated to be 16.91 $\mathrm{mW}$. Dauksevicius et al. [92] used two central stoppers instead of different length. When excited at $1 \mathrm{~g}$, the output power was increased up to $90 \%$ for all clearance values when compared to the individual stoppers. $30-37 \mu \mathrm{W}$ was produced over a bandwidth of 8-9 $\mathrm{Hz}$ at the largest clearance of $2.5 \mathrm{~mm}$.

Vijayan et al. [93] replaced the use of central stopper with a spring element attached to the free end of the bottom piezoelectric beam. The output power was dependent on the clearance and thickness ratio (the power dropped when the thickness ratio approached 1 . The highest output power of $6 \mathrm{~mW}$ was obtained at a ratio of 0.168 and excitation of $0.2 \mathrm{~mm}$. However, there has been a concern that it would promote the wear and tear of the beam and generate significant noise. Therefore, Shih et al. [94] proposed the use of magnetic stopper that caused the same effect without actual contact. The output power could be enhanced up to 10.41 times the value for harvester without the stopper structure. Unfortunately, the researchers reported that crack formed at the PZT patch after a few repetitions of experiment.

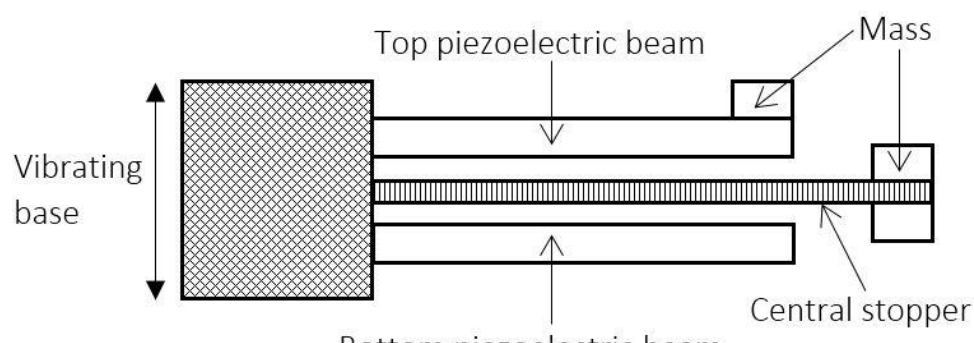

Figure 7. Schematic diagram of impact-enhanced energy harvester proposed by Ferarri et al. [91]

Liu et al. [95] combined the multi-modal and nonlinear configurations by adding a stopper to a 2-DOF piecewise linear MFC energy harvester. The schematic diagram is presented in Figure 8. The bandwidth was 5.2 times greater than that of the 2-DOF linear harvester without a resonator. The peak powers reached $429 \mu \mathrm{W}$ and $411 \mu \mathrm{W}$ at $21.4 \mathrm{~Hz}$ and $51.8 \mathrm{~Hz}$, respectively, when subjected to a harmonic excitation of $3 \mathrm{~ms}^{-2}$. This work can serve as a base for future studies involving other types of material and multi-DOF design. Maeguchi et al. [96] combined mechanical stoppers with a magnetic tuning method (see Figure 9). The stoppers increased the bandwidth as the distance to central piezoelectric beam reduced. The magnets had more influence on the frequency shift as they were getting closer to each other. Combining these two effects, the proposed energy harvester had broader bandwidth at low-frequency region. It is important to reduce damping due to contact by specifying the appropriate shape and material of the stoppers as well as the end mass. However, this configuration accelerates the fatigue failure rate, and this is a major challenge for impact-enhanced energy harvester employing PZT beams. Despite their superior piezoelectric properties, piezoceramics are generally very 
hard and brittle. Further study that focuses on increasing the durability of piezoelectric material is therefore recommended.

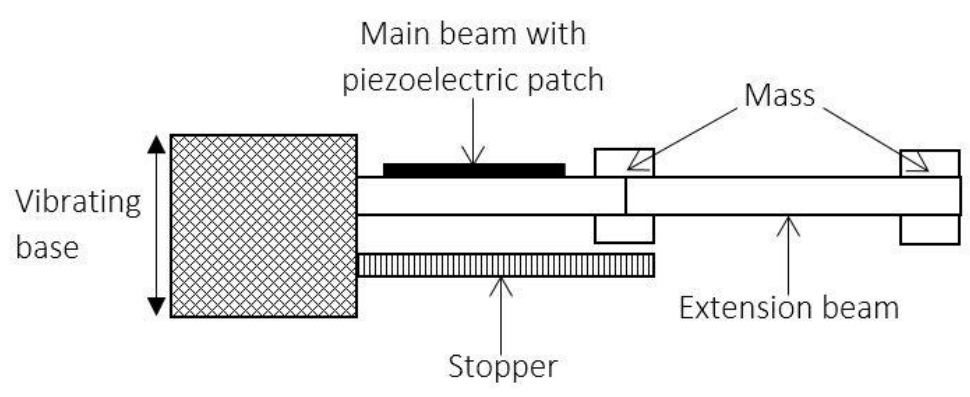

Figure 8. Schematic diagram of 2DOF piecewise linear energy harvester explored by Liu et al. [95]

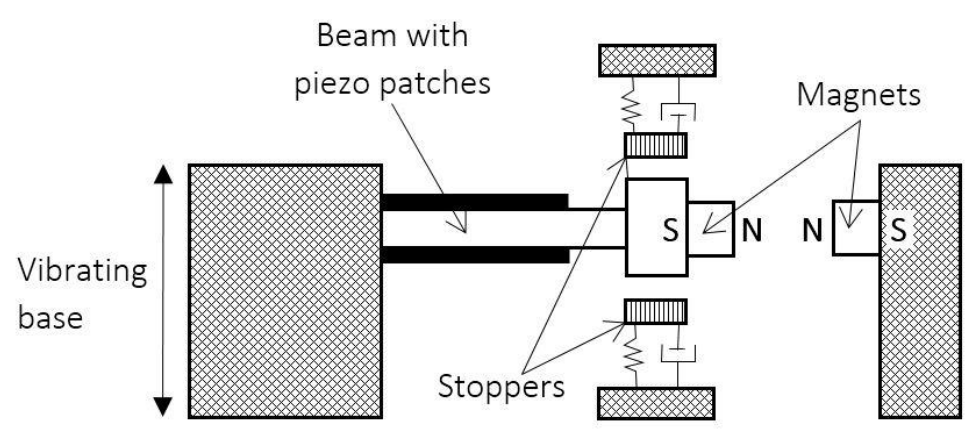

Figure 9. Schematic diagram of energy harvester with mechanical stoppers and magnets proposed by Maeguchi et al. [96].

\section{Multi-Stable Configuration}

Several attempts have been made to achieve multiple stable states by using the Duffing nonlinear oscillator. The nonlinearity of multi-stable energy harvester is demonstrated by the cubic spring restoring force that influences its hysteretic behaviour (spring hardening or softening). Jiang and Chen [97], and Daqaq [98] revealed that the monostable energy harvester did not perform well under random vibration excitation, suggesting that the configuration might only work with harmonic excitation. Ramlan et al. [99,100] found that the bistable configuration amplified the given input excitation. At a much lower excitation frequency than the natural frequency, the harvested energy was higher than that of its linear counterpart. This finding was experimentally proven by Cotton et al. [101] and Li et al. [102]. Pellegrini et al. [103] classified bistable energy harvesters based on their practicability for a smaller size. A prominent advantage of the bistable system is that the transition from one stable state to another at a high magnitude of excitation allows the device to have a large vibration amplitude. The gaining distance between two potential wells can amplify the amplitude of snap-through motion. However, the height of the potential barrier will increase accordingly; therefore, higher excitation is required. The great dependency of excitation level becomes a serious drawback which inhibits not only the performance of the bistable system but also other nonlinear energy harvesters [104].

Figure 10 represents the working principle of two-dimensional bistable energy harvester studied by Andó et al. [105]. It harvested $3.2 \mu \mathrm{W}$ which was 10 times larger 
than that of the linear system. Their magnetically coupled antiphase cantilevers produced $3.5 \mu \mathrm{W}$ which was twice of the output of nonlinear single beam and 10 times more than that of a linear system [106]. However, both designs were extremely excited at $12.7 \mathrm{~g}$ and $8.2 \mathrm{~g}$. Several magnetically coupled energy harvesters have also been developed by [107109]. Unfortunately, the issue occurred when the harvesters were fed with small excitations was not properly addressed. However, $\mathrm{Wu}$ and Lee [110] proposed a magnetically coupled energy harvester with folded cantilever design (2-DOF) to improve space and output power. The cantilevers drove each other due to the magnetic force, resulting in greater deflection upon ambient excitation. At a constant excitation of $0.1 \mathrm{~g}$, the total output power reached $18.45 \mu \mathrm{W}$ at $30 \mathrm{~Hz}$. But there was a lack of evidence for its robustness and durability. Further study should focus on the structural material.
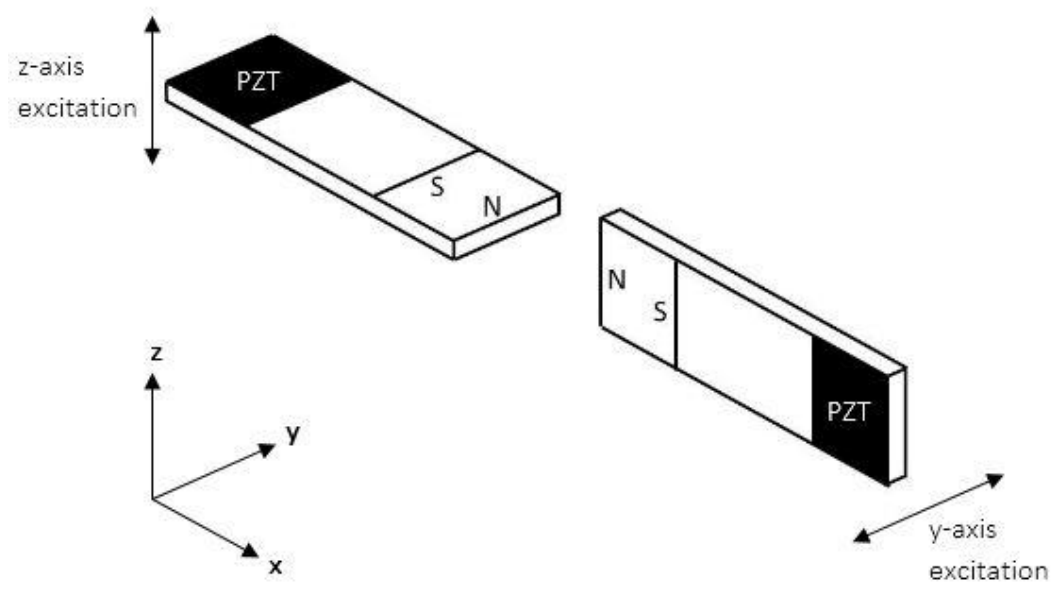

Figure 10. Working principle of two-dimensional bistable energy harvester studied by Andó et al. [105].

Over the past few years, there has been an increasing interest in a more complex multi-stable energy harvesting system to have shallower potential wells. Zhou et al. [111, 112] proposed a tristable energy harvester. With stochastic excitation at $4 \mathrm{~ms}^{-2}$, it produced $22 \mathrm{~V}$ at $5 \mathrm{~Hz}$ while bistable energy harvester hardly generated $5 \mathrm{~V}$, most probably because it was only oscillating intra-well due to deeper potential wells. Panyam and Daqaq [113] described that even when the excitation was inadequate to exhibit interwell oscillations, the bandwidth was significantly improved due to the presence of two resonant frequencies: one associated with the middle potential well and the other with the outer potential wells. A few researchers $[114,115]$ engaged with quadstable piezoelectric energy harvester which was more capable to snap from one stable position to another. In addition, Wang et al. [116] proposed an impact-driven quinstable piezoelectric energy harvester to further decrease the frequency threshold for jumping between potential wells without increasing the vibration amplitude. The schematic diagram of the bottom view is illustrated in Figure 11. It generated a maximum of $5.16 \mathrm{~mW}$ at $7 \mathrm{~Hz}$ with a harmonic excitation of $4 \mathrm{~ms}^{-2}$. Nevertheless, it is always challenging to design multi-stable devices as they require a precise parameter choice. Reducing the depth of potential wells for them to perform at low excitation amplitude causes a significant drop in the corresponding electrical output response. Furthermore, multi-stable energy harvester is more complex than other systems. Past breakthroughs of multi-modal approach and nonlinear dynamics encourage Wang and Tang [117] to propose a magnetically coupled 2-DOF bistable 
piezoelectric energy harvester. It generated $5.5 \mathrm{~mW}$ at $37 \mathrm{~Hz}$ when harmonically excited at $4 \mathrm{~ms}^{-2}$. However, the resistive load influenced the nonlinear response peak in which its optimum value not only shifted the peak to the highest frequency range but also reduced the bandwidth.

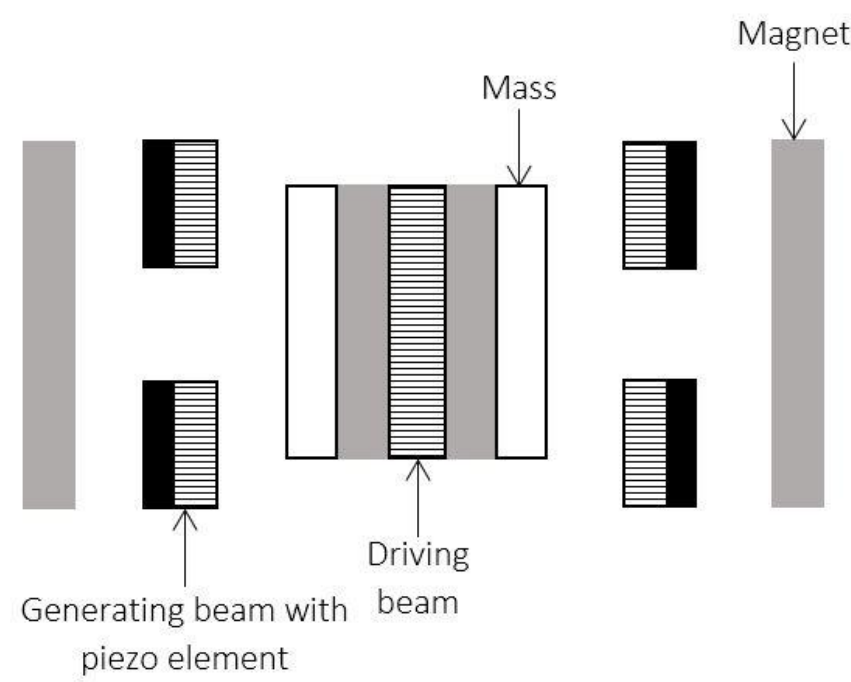

Figure 11. Schematic diagram of impact-driven quinstable energy harvester developed by Wang et al. [116] (bottom view).

\section{Hybrid Configuration}

Other than a single transduction mechanism, researchers have also been dealing with hybrid piezoelectric (voltage generator) and electromagnetic (current generator) harvester. Green et al. [118] stated that electromagnetic harvester was more capable of harvesting energy from a very low-frequency ambient. When the electromagnetism is introduced to the piezoelectric generator, the increase in damping decreases the vibration amplitude of the piezoelectric counterpart as well as the output power. Hence, electromagnetic harvester must contribute more energy to compensate for this loss. The maximum output power of a hybrid device is achieved when the total electrical damping matches the mechanical damping. The total electrical damping is controlled by the load resistance. In specific, the piezoelectric and electromagnetic resistance values should match the beam impedance and coil resistance, respectively, for maximum output power. Challa et al. [119] proposed a linear hybrid energy harvester. With harmonic excitation at $21.6 \mathrm{~Hz}$, the hybrid device produced $332 \mu \mathrm{W}$ which was at least $30 \%$ higher compared to that generated by the standalone piezoelectric and electromagnetic harvester. Lallart and Inman [120] introduced Figure of Merit (FOM) given by $k^{2} Q_{M}$. When the FOM exceeded a critical value, the bandwidth would be enhanced. Even when the FOM was low, the hybrid arrangement exhibited the larger output power and bandwidth features as those reported in the previous study. The harmonically excited hybrid system produced $1.25 \mathrm{~mW}$ at $17 \mathrm{~Hz}$ with an amplitude of $0.1 \mathrm{~g}$. It was $10 \%$ and $30 \%$ higher than those of pure piezoelectric harvester and electromagnetic element alone, respectively. Wang et al. [121] added a spring connected magnet to the free end of the piezoelectric cantilever to amplify the excitation of electromagnetic transduction mode (see Figure 12). It generated $2.16 \mathrm{~mW}$ and $0.9 \mathrm{~mW}$ at $68 \mathrm{~Hz}$ and $92 \mathrm{~Hz}$, respectively, when harmonically excited at $1.41 \mathrm{~ms}^{-2}$. Resali and Salleh [122] incorporated PTFE extension into the piezoelectric 
beam to reduce its natural frequency to $50 \mathrm{~Hz}$. The schematic diagram is represented in Figure 13. The proposed hybrid energy harvester produced $3 \mathrm{~mW}$ upon excitation at $0.25 \mathrm{~g}$ rms.

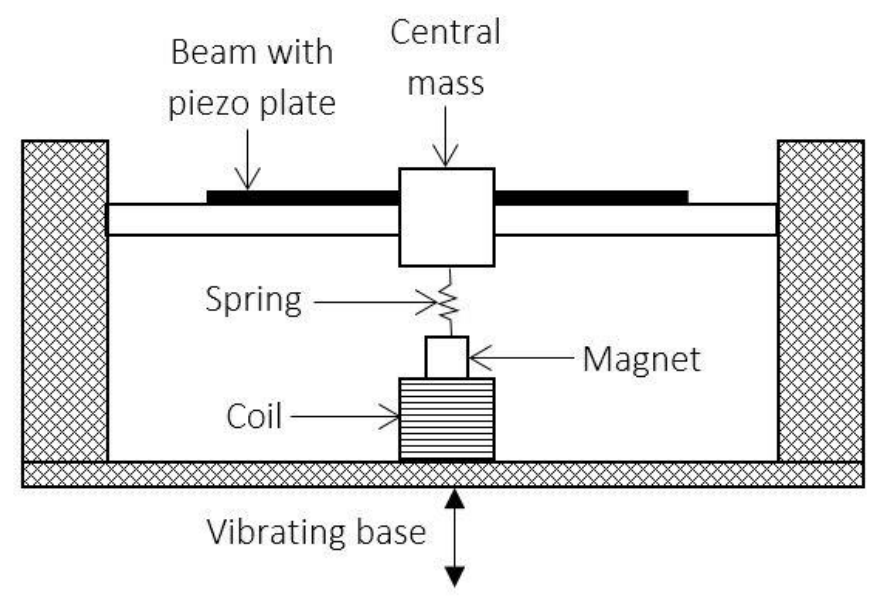

Figure 12. Schematic diagram of 2DOF hybrid energy harvester proposed by Wang et al. [121].

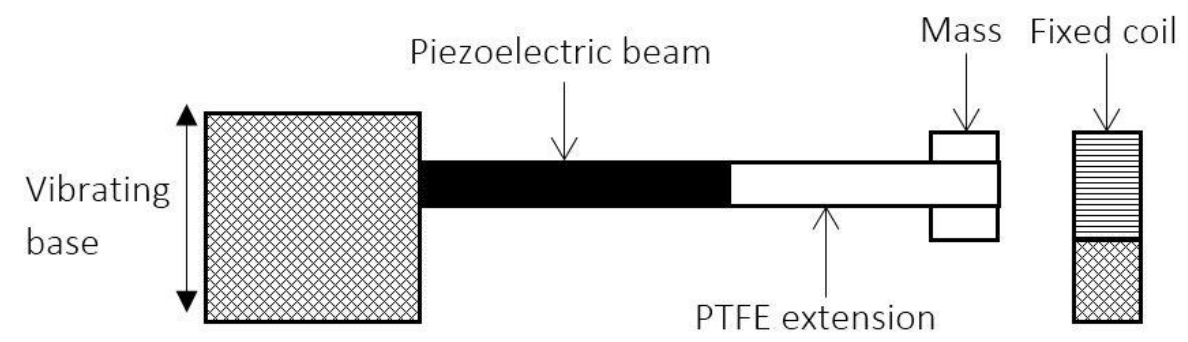

Figure 13. Schematic diagram of hybrid energy harvester with PTFE extension proposed by Resali and Salleh [122].

To further enhance the performance in a low-frequency environment, researchers have explored the nonlinear hybrid harvester. Shan et al. [123] fixed a magnetic suspension system at the free end PZT cantilever. The top and bottom magnets were oriented to repel the middle magnet, providing enough nonlinear restoring force for suspension. The harmonically excited harvester generated $7.2 \mathrm{~mW}$ and $16.4 \mathrm{~mW}$ at $8.5 \mathrm{~Hz}$ and $16 \mathrm{~Hz}$, respectively, with input acceleration of $5 \mathrm{~ms}^{-2}$. An appreciable amount of power could be harvested in the range of 6-20 Hz. The effect of magnetic interaction was not clearly understood until 2016 where $\mathrm{Xu}$ et al. [124] proposed another 2DOF magnetically coupled hybrid device with a tuneable feature. This was realised by interacting the magnetic end mass of piezoelectric cantilever and the magnetic ring oscillator surrounded by an induction coil. With harmonic excitation of $2 \mathrm{~ms}^{-2}, 1.4 \mathrm{~mW}$ was caused by the magnetic oscillator at $22.6 \mathrm{~Hz}$. It was $16.7 \%$ better than that of the single electromagnetic harvester. In fact, it already outperformed the combined linear piezoelectric and electromagnetic harvesters by 2.36 times at the same excitation condition. Meanwhile, $2.82 \mathrm{~mW}$ was contributed by the piezoelectric generator at $25.6 \mathrm{~Hz}$ which was $833 \%$ higher than its individual performance! Xu et al. [125] then continued to explore the proposed energy harvester's structure and reported that $2.96 \mathrm{~mW}$ 
and $4.76 \mathrm{~mW}$ were generated at $23.6 \mathrm{~Hz}$ and $32.8 \mathrm{~Hz}$, respectively, with the same amount of excitation amplitude. Li et al. [126] proposed another magnetically coupled hybrid device. With harmonic excitation of $0.2 \mathrm{~g}$, it generated $440 \mu \mathrm{W}$ at $113.5 \mathrm{~Hz}$ which was $10 \%$ higher than without magnetic interaction. This amount possibly fulfils the minimum power requirement of a sensor node in wireless sensor networks [127]. But, the frequency responses of the hybrid harvester did not significantly demonstrate an improved halfpower bandwidth as claimed. There was only a mere increase of $1.2 \mathrm{~Hz}$ from the linear half-power bandwidth. The emphasis on using higher acceleration to get larger output power and bandwidth is not practical for low-frequency applications since most of them have low vibration amplitude. This report could be more interesting if there are other relevant suggestions for industrial implementation. Kwon et al. [128] offered a new hybrid design employing the impact-based configuration with an additional cantilever which produced $3.16 \mathrm{~mW}$ and $2.6 \mathrm{~mW}$ at $31 \mathrm{~Hz}$ and $62 \mathrm{~Hz}$, respectively. The working principle is shown in Figure 14. The integration with the frequency up-conversion method could contribute to an effective energy harvesting even at extremely low frequency (less than $10 \mathrm{~Hz}$ ). This claim was indeed supported by the work presented by Edwards et al. [129]. Their nonlinear hybrid harvester produced a $49.8 \mu \mathrm{W}$ at $5 \mathrm{~Hz}$ with broad-spectrum random excitation of $1 \mathrm{~g}$. However, it was unknown whether the wideband characteristic was achieved.

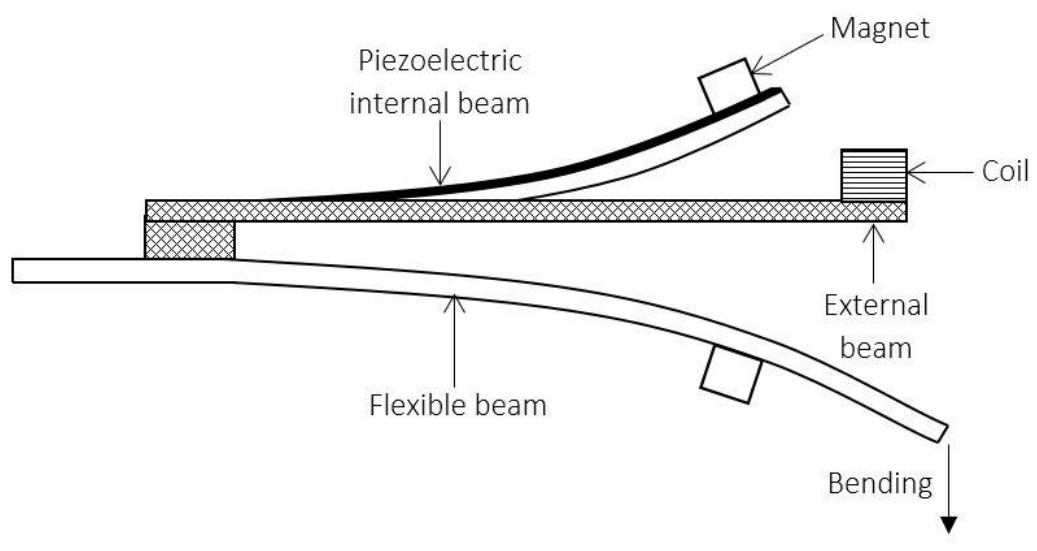

Figure 14. Schematic diagram of impact-enhanced hybrid energy harvester presented by Kwon et al. [128].

\section{MULTI-DIRECTIONAL ENERGY HARVESTING}

In most studies, it is commonly assumed that the ambient vibration only excites an energy harvester from a single direction. However, low-frequency energy sources such as building vibration and human motion are normally complex and multi-dimensional. Therefore, it is necessary for an energy harvester to demonstrate better environment adaptability. Chen et al. [130] remedied this issue by proposing a dandelion-like multidirectional energy harvester with 13 bimorphs. A significant level of output power was recorded in most excitation directions. $280 \mu \mathrm{W}$ was harvested at $22 \mathrm{~Hz}$ with excitation of $0.28 \mathrm{~mm}$ at an angle of $1.5 \mathrm{rad}$ in the $\mathrm{XY}$ plane. However, the total output power reduced tremendously in some excitation directions. This issue should be properly addressed in future works. Furthermore, the overall outcome needs to justify the generous material usage for this proposed design. Yang and $\mathrm{Zu}$ [131,132] placed a PZT plate in between two bow-shaped aluminium plates. This arrangement constituted a flexural centre that 
deformed when vibration was applied, causing the PZT plate to generate electricity in compressive mode. The output voltage was maintained at a significant level for all tested directions of excitation. An entirely different result was observed for a conventional cantilever type harvester whereby more than $90 \%$ of the vibration energy was lost at $90^{\circ}$ angle of excitation. The harvester produced $1.74 \mathrm{~mW}$ with a sinusoidal excitation of $0.2 \mathrm{~g}$ at $17 \mathrm{~Hz}$. But, the issue of space occupied by this harvester was not adequately addressed. It can be more than $150 \mathrm{~mm}$ long even without the clamp structure. This raises the question whether the structure can be made smaller while maintaining its performance. Park et al. [133] attached an asymmetric aluminium mass at the free end of the vertical piezoelectric beam. $7.5 \mathrm{~mW}$ and $1.4 \mathrm{~mW}$ were produced at $34 \mathrm{~Hz}$ and $40.5 \mathrm{~Hz}$ when it was excited from $z$-axis and $x$-axis, respectively. But the excitation was too high i.e. $10 \mathrm{~ms}^{-2}$ and the power reduced tremendously when the amplitude was lowered especially in the $z$-axis direction. A source of weakness which could have affected the lifetime and environment adaptability is the lack of mechanical robustness due to brittle piezoelectric material. Thus, more research is required to determine the efficacy of this harvester. It should be compared to the conventional configuration not only in terms of harvesting capability but also the durability and the fatigue development subjected to dynamic bending stress.

Wang et al. [134] adopted the principle of mechanical energy buffering to achieve the frequency up-conversion and proposed a cantilever-spring energy harvester with magnetic interaction at the free end to benefit from bi-directional vibrations. The energy harvester is illustrated in Figure 15 where $14 \mathrm{~V}$ was produced at $33 \mathrm{~Hz}$ due to $z$-axis excitation, whereas $9.6 \mathrm{~V}$ was measured at the same frequency when it was excited horizontally with unknown excitation amplitude. A minimum of $5 \mathrm{~V}$ can be harvested approximately between $28.5-33.5 \mathrm{~Hz}$ and $29.5-36.5 \mathrm{~Hz}$ when excited in vertical and horizontal directions, respectively. However, there is no benchmark set in the investigation. It would have been more convincing if the researchers compared the performance with that of a control energy harvester.

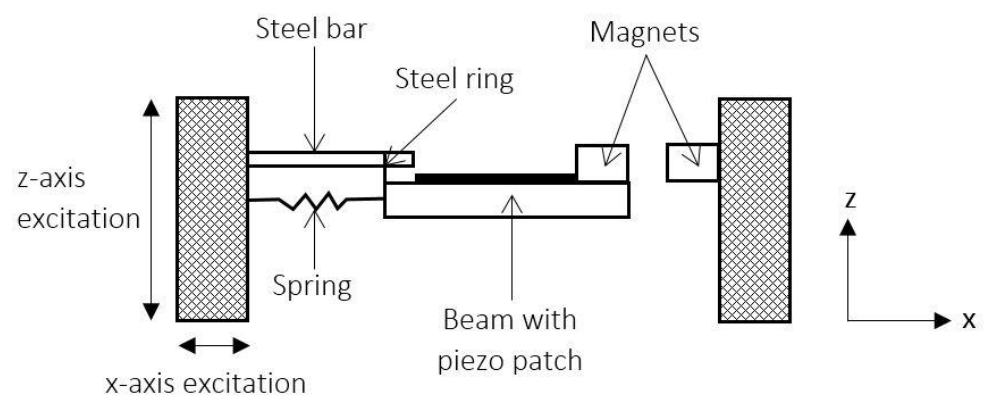

Figure 15. Bidirectional energy harvester with spring and magnetic coupling presented by Wang et al. [134].

In recent work, Ceponis et al. [135] proposed fixing the piezoelectric beam at a minimum angle, $\alpha$ of 1.13 rad to allow for a more rotational moment (see Figure 16). A $0.1 \mathrm{~ms}^{-2}$ excitation in z-direction generated $16.85 \mu \mathrm{W}$ at most at $26.65 \mathrm{~Hz}$. Meanwhile, $15.94 \mu \mathrm{W}$ was produced at $11.25 \mathrm{~Hz}$ when excited with the same amplitude in the $\mathrm{y}-$ direction. The proposed energy harvester also had a stable electrical characteristic even with an impact-based excitation in both directions. One question that needs to be asked is, however, whether it really eliminates the requirement of exact excitation directions as concluded by the researchers. Apparently, they had overlooked the fact that the reported 
results were only obtained from certain directions of excitation. The findings from this work therefore, need to be interpreted with caution.

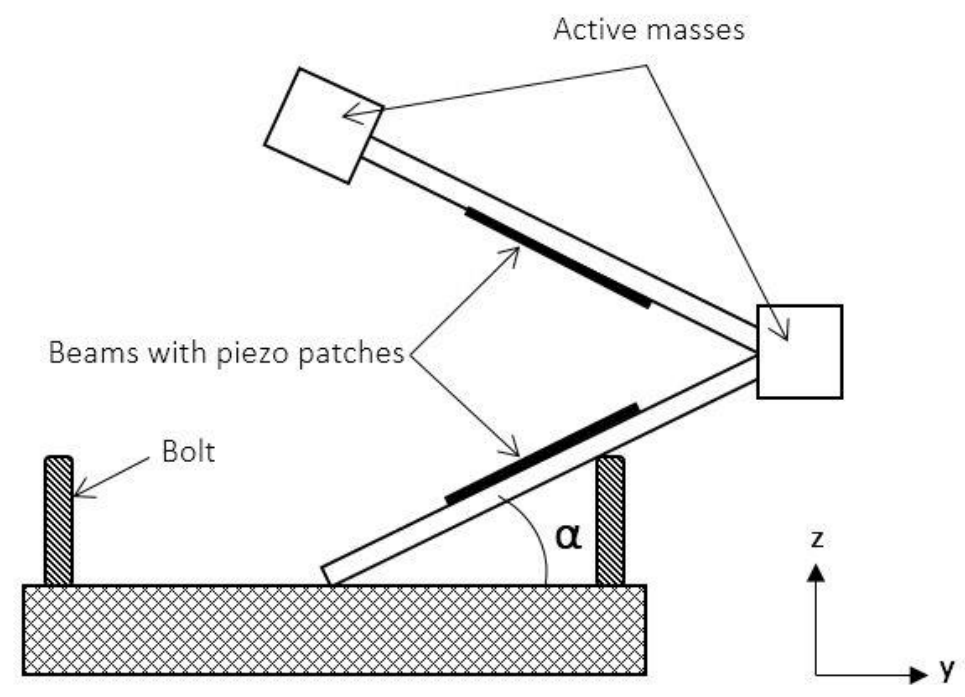

Figure 16. Bidirectional energy harvester with an inclined angle and active masses proposed by Ceponis et al. [135].

\section{EFFECTIVE STRATEGIES AND KEY FACTORS}

A comprehensive summary of selected work including the calculated power density is provided in Table 3 and used to determine the effective strategies for developing highperformance piezoelectric energy harvester at low frequency. Assuming a linear relationship, the power density is normalised at an acceleration of $1 \mathrm{~g}$. The power density was plotted against excitation frequency as presented in Figure 17.

Most works fall in the second quadrant of the figure. It indicates that the recent developments are inclined towards generating more power from low frequency and low amplitude ambient vibration with less piezoelectric material. It is apparent that the design proposed by Lam and Salleh $[68,69]$ results in the highest power density per $g$ among others. The normalised amount is computed to be $1085 \mu \mathrm{W} / \mathrm{mm}^{3} / \mathrm{g}$. The researchers utilised a low-cost material with respect to PZT to improve the harvester's performance at low frequency. Perhaps this idea is stemming from the amplification of input energy by the extension beam. Future work can be undertaken with different slotted beam materials and geometries. However, the extension of the beam increases the overall size as well. Thus, its application in limited space is questionable. The rank is followed by the bidirectional energy harvester with an inclined angle and active masses proposed by Ceponis et al. [135]. The normalised power density is $465.06217 \mu \mathrm{W} / \mathrm{mm}^{3} / \mathrm{g}$. It is now almost certain that the rotational moment due to the use of active masses and the inclination contributes to higher strain energy of piezoelectric material. Despite this promising result, the question remains about the aftermath of continuous knocking between the piezoelectric beam and the fixed bolts. It is known that piezoceramics are brittle. Therefore, this is an important issue for future research. The 2-DOF right angle coupled energy harvester designed by $\mathrm{Xu}$ et al. [72] occupies the third rank. The significant normalised power density of $217 \mu \mathrm{W} / \mathrm{mm}^{3} / \mathrm{g}$ is likely due to the increase in bending induced by the extension at the end of the piezoelectric beam. As mentioned 
before, piezoceramics are prone to crack or total breakage. Hence, the lifetime of piezoelectric harvester might be reduced due to fatigue failure resulting from overbending.

Table 3. A comprehensive summary of selected work.

\begin{tabular}{|c|c|c|c|c|c|c|c|c|}
\hline \multirow[b]{2}{*}{ Strategy } & \multirow[b]{2}{*}{$\begin{array}{l}\text { Piezo } \\
\text { material }\end{array}$} & \multirow[b]{2}{*}{ Material } & \multicolumn{3}{|c|}{ Input } & \multirow{2}{*}{$\begin{array}{l}\text { Output } \\
\text { power } \\
(\mu \mathrm{W})\end{array}$} & \multirow{2}{*}{$\begin{array}{c}\text { Power } \\
\text { density } \\
\left(\mu \mathrm{W} / \mathrm{mm}^{3}\right)\end{array}$} & \multirow[b]{2}{*}{ Ref. } \\
\hline & & & $\begin{array}{c}\text { Volume } \\
\left(\mathrm{mm}^{3}\right)\end{array}$ & Excitation & $\begin{array}{l}\text { Freq. } \\
(\mathrm{Hz})\end{array}$ & & & \\
\hline \multirow{5}{*}{$\begin{array}{l}\text { Optimum } \\
\text { shape and } \\
\text { size }\end{array}$} & PZT & S. Steel & 6500 & & 13.4 & 6500 & 1 & [49] \\
\hline & PSI-5A4E & S. Steel & & $0.2 \mathrm{~g}$ & 50 & & 9.64 & [56] \\
\hline & PSI-5H4E & & 347 & & 85 & 4876 & 14.0534 & [58] \\
\hline & PSI-5H4E & & 893.2 & & 105 & 7607 & 8.5166 & [58] \\
\hline & PZT-5H & Aluminium & 950 & $0.4 \mathrm{~N}$ & 58.5 & 11079 & 11.6621 & [61] \\
\hline \multirow{3}{*}{$\begin{array}{l}\text { Optimum } \\
\text { multi-layer } \\
\text { structure }\end{array}$} & PZT-5H & S. Steel & 75.9 & $0.41 \mathrm{~g}$ & 64.5 & 97.9 & 1.2899 & [64] \\
\hline & PZT-5H & S. Steel & 227.7 & $0.41 \mathrm{~g}$ & 64.5 & $\begin{array}{c}458.7 \\
6\end{array}$ & 2.0143 & [65] \\
\hline & PZT & Aluminium & 1500 & & 20 & 1250 & 0.8333 & [67] \\
\hline \multirow{5}{*}{$\begin{array}{l}\text { Multi-DOF } \\
\text { config. }\end{array}$} & PZT & Brass & 206.4 & $0.25 \mathrm{~g}$ & 30 & 56000 & 271.3178 & [68] \\
\hline & PZT-CN & S. Steel & 326.4 & & 69 & 7800 & 23.8971 & [70] \\
\hline & PZT-5A & S. Steel & 394 & $1 \mathrm{~g}$ & 22.8 & 10000 & 25.3807 & [71] \\
\hline & PZT & Titanium & 240 & $0.26 \mathrm{~g}$ & 38.3 & 13540 & 56.4167 & [72] \\
\hline & PZT & Brass & 480 & $1 \mathrm{~g}$ & 78.3 & 67700 & 141.0417 & [74] \\
\hline \multirow{3}{*}{$\begin{array}{l}\text { Cantilever } \\
\text { array } \\
\text { config. }\end{array}$} & PZT & Aluminium & 2327.5 & $0.1 \mathrm{~g}$ & 94.5 & 57.5 & 0.0247 & [79] \\
\hline & PZT-5H & Composite & 5760 & $0.1 \mathrm{~g}$ & 99 & 430 & 0.0747 & [80] \\
\hline & PVDF & $\begin{array}{l}\text { Poly- } \\
\text { propylene }\end{array}$ & 46.8 & $2 \mathrm{~mm}$ & 27.2 & 53 & 1.1325 & [82] \\
\hline \multirow{5}{*}{$\begin{array}{l}\text { Impact- } \\
\text { enhanced } \\
\text { config. }\end{array}$} & PZT & S. Steel & & $1 \mathrm{~g}$ & 20 & 16910 & & [91] \\
\hline & PZT-5H & PET PEN & 16.64 & $1 \mathrm{~g}$ & 38.1 & 37 & 2.2240 & [92] \\
\hline & PZT & & 98 & $0.2 \mathrm{~mm}$ & 29.09 & 6000 & 61.2250 & [93] \\
\hline & PZT & S. Steel & & & 13.5 & 0.1 & & [94] \\
\hline & $\begin{array}{l}\text { MFC } \\
\text { M2814-P2 }\end{array}$ & Aluminium & 117.6 & $0.31 \mathrm{~g}$ & 21.4 & 429 & 3.6480 & [95] \\
\hline \multirow{6}{*}{$\begin{array}{l}\text { Multi- } \\
\text { stable } \\
\text { config. }\end{array}$} & $\mathrm{PZT}$ & Aluminium & & $12.73 \mathrm{~g}$ & & 4.5 & & [105] \\
\hline & PZT & Aluminium & & $8.2 \mathrm{~g}$ & & 3.5 & & [106] \\
\hline & PVDF & PMMA & & $0.1 \mathrm{~g}$ & 30 & 18.45 & & [110] \\
\hline & MFC & Beryllium & 235.2 & $0.41 \mathrm{~g}$ & 7 & 5160 & 21.9388 & [116] \\
\hline & M2807-P2 & Bronze & & & & & & \\
\hline & $\begin{array}{l}\text { MFC } \\
\text { M2814-P2 }\end{array}$ & & 235.2 & $0.41 \mathrm{~g}$ & 37 & 5500 & 23.3844 & [117] \\
\hline \multirow[t]{6}{*}{$\begin{array}{l}\text { Hybrid } \\
\text { config. }\end{array}$} & PZT & $\begin{array}{l}\text { Carbon } \\
\text { Fibre }\end{array}$ & 230.4 & & 21.6 & 332 & 1.4140 & [119] \\
\hline & PZT-5H & & 320 & $0.51 \mathrm{~g}$ & 16 & 16400 & 51.2500 & [120] \\
\hline & PZT & Brass & 206.4 & $0.25 \mathrm{~g}$ & 50 & 3000 & 14.5349 & [122] \\
\hline & PZT-5H & $\begin{array}{l}\text { Phosphor } \\
\text { Bronze }\end{array}$ & 320 & $0.2 \mathrm{~g}$ & 32.8 & 4760 & 14.8750 & [125] \\
\hline & PZT-5H & $\begin{array}{l}\text { Phosphor } \\
\text { Bronze }\end{array}$ & 400 & $0.2 \mathrm{~g}$ & 25.6 & 2820 & 7.0500 & [124] \\
\hline & PZT & S. Steel & 256 & $0.2 \mathrm{~g}$ & 113.5 & 440 & 1.7188 & [126] \\
\hline \multirow{4}{*}{$\begin{array}{l}\text { Multi- } \\
\text { directional } \\
\text { energy } \\
\text { harvesting }\end{array}$} & PZT-5H & $\begin{array}{l}\text { Beryllium } \\
\text { Bronze }\end{array}$ & 1123.2 & $0.28 \mathrm{~mm}$ & 22 & 280 & 0.2493 & [130] \\
\hline & PZT-5A & Aluminium & 420 & $0.2 \mathrm{~g}$ & 17 & 1739 & 4.1416 & [131] \\
\hline & PZT & & 259.2 & $1.02 \mathrm{~g}$ & 34 & 7500 & 28.9352 & [133] \\
\hline & PZT & Aluminium & 3.6 & $0.01 \mathrm{~g}$ & 26.65 & 16.85 & 4.6806 & [135] \\
\hline
\end{tabular}




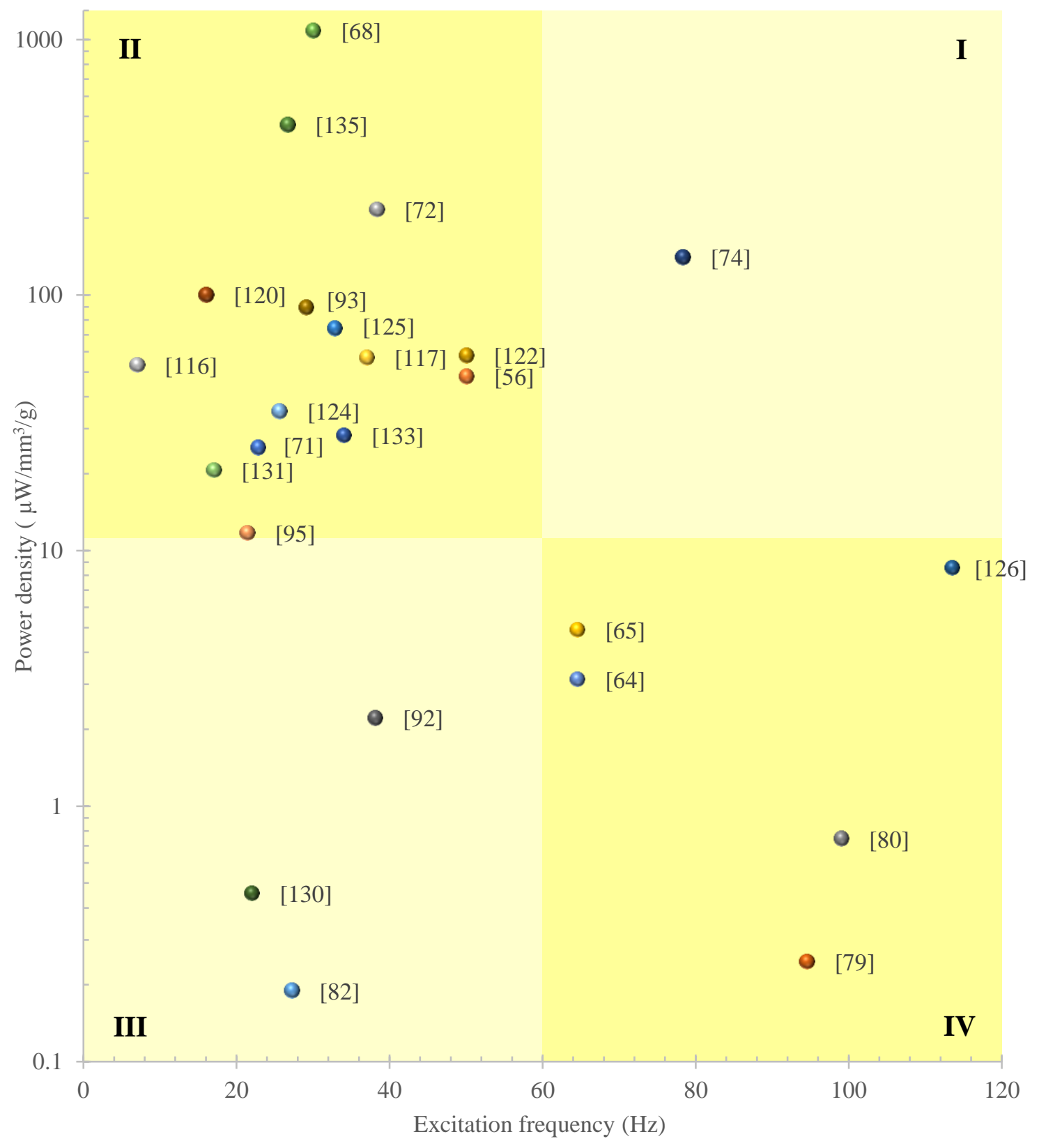

Figure 17. Comparison of power density per weight of selected work at the corresponding excitation frequency.

The fourth rank is earned by the 2-DOF harvester developed by Wang et al. [74] with a normalised power density of $141 \mu \mathrm{W} / \mathrm{mm}^{3} / \mathrm{g}$. Their design employs the same concept as that of the first-ranked energy harvester which is the amplification of input vibration by adding a spring at the base. But it is important to note that it falls on the first quadrant. Thus, future work is required to comprehensively compare these two input amplification methods. Besides producing a large power density, these multi-modal energy harvesters are exhibiting broader bandwidths. The hybrid energy harvester proposed by Shan et al. [120] is at the fifth place with a normalised power density of $101 \mu \mathrm{W} / \mathrm{mm}^{3} / \mathrm{g}$. The nonlinear impact-enhanced harvester developed by Vijayan et al. 
[93] secures the sixth place with a normalised power density of $90 \mu \mathrm{W} / \mathrm{mm}^{3} / \mathrm{g}$. Seemingly, there is a trade-off between output power and bandwidth for an energy harvester.

The harvesters by Dayou et al. [82] exhibit relatively low normalised power density of only $0.15 \mu \mathrm{W} / \mathrm{mm}^{3} / \mathrm{g}$ despite a very high base displacement of $2 \mathrm{~mm}$. This may be due to the significantly low electromechanical coupling factor of PVDF material compared to that of PZT. The reasoning behind this material selection has not been explained by the researchers. Therefore, it is important to consider the characteristic of piezoelectric material in designing a practical energy harvester. It is also worth pointing out the normalised power density of $0.46 \mu \mathrm{W} / \mathrm{mm}^{3} / \mathrm{g}$ which belongs to dandelion-like harvester proposed by Chen et al. [130]. It was likely not the best way to harvest energy from a common source with one dominant excitation direction. However, the proposed energy harvester may be more useful if the excitation comes from multiple directions.

Several key factors are identified in the analysis. The first key factor is the excellent characteristics of piezoelectric material. Superior strain coefficient and voltage constant are basic indicators for higher energy density. However, this characteristic alone does not assure the performance of energy harvester. Higher dielectric constant would promote the capacitive characteristic and larger electromechanical coupling factor implies higher energy conversion efficiency. The sharpness of resonance frequency is achieved through high mechanical quality factor. Although the use of PZT is popular, there is a wide range of products offered by manufacturers to cater to different conditions and requirements of energy harvesting technology. The second key factor is associated with optimised geometry for high strain energy density. Usually, the cantilever configuration is adopted for an energy harvester with a rectangular beam. But numerous studies have reported that a triangular beam outperforms a rectangular beam in terms of internal strain energy density, leading to higher output power ( $4 \times$ increase). However, it does not necessarily give more favourable result if the size is not optimised. Yet, energy harvester with triangular PZT beam is not extensively studied, which is likely due to the technical challenge while cutting the brittle rectangular beam to the triangular one. The third key factor is excellent flexibility. PZT is very stiff and prone to fracture during operation. Coating the PZT beam with rubber material can reduce its stiffness and natural frequency by $8.33 \%$. The next equally important key factor is the high excitation amplitude. Nevertheless, the acceptable vibration level for industrial applications is generally very low. For example, according to ISO 10816-3, the vibration level of a healthy electrical motor operating at $50 \mathrm{~Hz}$ should not exceed $0.5 \mathrm{~g}$. Hence, amplifying the excitation can escalate the process, for example by implementing a multi-DOF configuration. The frequency spectrum of ambient vibrations is very broad. Consequently, a piezoelectric energy harvester might become invaluable and unreliable when there is a sudden variation of the excitation frequency. In turn, this leads to the last key factor which is broad bandwidth. Worldwide researchers have explored various configurations to enhance the bandwidth. Unfortunately, the challenging part is keeping the complexity tolerable. Apart from focusing on quality and performance, the technology should also be affordable.

\section{CONCLUSION}

Various studies have been conducted in the last two decades to improve the performance of a piezoelectric energy harvester at low frequency. However, its application is limited due to low output power. This paper reviewed the strategies implemented to improve the output power such as the selection of piezoelectric materials for low-frequency 
applications as well as optimisation of geometry in terms of shape, size and structure. Based on the comprehensive summary of the normalised power density at $1 \mathrm{~g}$ acceleration, it was found that most works fell in the second quadrant of low frequency and high power density. The maximum value was around $1 \mathrm{~mW} / \mathrm{mm}^{3} / \mathrm{g}$. It indicates that the recent developments are inclined towards generating more power from low frequency and low amplitude ambient vibration with less piezoelectric material. The analysis from the previous works suggests that adding a single DOF system in the form of an extension beam or a spring to the piezoelectric beam can dramatically enhance the normalised power density. Additionally, the resulting multi-modal energy harvester exhibits broader bandwidth when its multiple resonance peaks get closer. The findings indicate that the anticipated performance of a piezoelectric energy harvester can be achieved despite the trade-off between output power and operating bandwidth. However, high excitation amplitude and generous material usage do not warrant high output power. Based on these findings, five key factors have been identified to ensure high performance at low frequency i.e. excellent characteristics, optimised geometry for high strain energy density, excellent flexibility, high excitation amplitude and broad bandwidth.

\section{ACKNOWLEDGEMENT}

This work was supported by the Ministry of Higher Education Malaysia, Fundamental Research Grant Scheme grant number 20140133FRGS.

\section{REFERENCES}

[1] Platt SR, Farritor S, Haider H. On low-frequency electric power generation with PZT ceramics. IEEE/ASME Transactions on Mechatronics, 2005;10(22):240-252.

[2] Alrashdan MHS, Hamzah AA, Majlis B. Design and optimisation of cantilever based piezoelectric micro power generator for cardiac pacemaker. Microsystem Technology, 2015;21(8):1607-1617.

[3] Steingart D. Power sources for wireless sensor networks. In: Priya S, Inman DJ, editors. Energy Harvesting Technologies, US: Springer, 2009, p 267-286.

[4] Park G, Farinholt K, Farrar C, Rosing T, Todd M. Powering wireless SHM sensor nodes through energy harvesting. In: Priya S, Inman DJ, editors. Energy Harvesting Technologies, US: Springer, 2009, p 493-506.

[5] Kim GW. Piezoelectric energy harvesting from torsional vibration in internal combustion engines. International Journal of Automotive Technology, 2015;16(4): 645-651.

[6] Gatti G, Brennan MJ, Tehrani MG, Thompson DJ. Harvesting energy from the vibration of a passing train using a single-degree-of-freedom oscillator. Mechanical System and Signal Processing, 2016;66-67:785-792.

[7] González JL, Rubio A, Moll F. Human powered piezoelectric batteries to supply power to wearable electronic devices. International Journal of the Society of Material Engineering for Resources, 2002;10(1):34-40.

[8] Jung WS, Lee MJ, Kang MG, Moon HG, Yoon SJ, Baek SH, Kang CY. Powerful curved piezoelectric generator for wearable applications. Nano Energy, 2015;13:174-181.

[9] Huang T, Wang C, Yu H, Wang H, Zhang Q, Zhu M. Human walking-driven wearable all-fiber triboelectric nanogenerator containing electrospun polyvinylidene fluoride piezoelectric nanofibers. Nano Energy, 2015;14:226-235. 
[10] Nousiainen JO. Piezoelectric kinetic energy harvester. U.S. Patent 20100045241. February 25, 2010.

[11] Paradiso JA, Starner T. Energy scavenging for mobile and wireless electronics. IEEE Pervasive Computing, 2005 4(1):18-27.

[12] Wang ZL, Song J. Piezoelectric nanogenerators based on zinc oxide nanowire arrays. Science, 2006;312(5771):242-246.

[13] Gao PX, Song J, Liu J, Wang ZL. Nanowire piezoelectric nanogenerators on plastic substrates as flexible power sources for nanodevices. Advance Material, 2007;19:67-72.

[14] Nuawi MZ, Ismail AR, Nor MJM, Rahman MM. A comparative study of wholebody vibration exposure in train and car passengers: A case study in Malaysia. International Journal of Automotive and Mechanical Engineering, 2011;4:490-503.

[15] Ismail AR, Abdullah SNA, Abdullah AA, Deros BM. Whole-body vibration exposure of Malaysian taxi drivers. International Journal of Automotive and Mechanical Engineering, 2015;11:2786-2792.

[16] Jain A, Kumar S, Kharb A. COMSOL multiphysics simulation of piezoelectric sensor for energy harvesting from railway tracks. International Journal of Recent Technology and Engineering, 2019;8(2):5446-5452.

[17] Li M, Jing X. Novel tunable broadband piezoelectric harvesters for ultralowfrequency bridge vibration energy harvesting. Applied Energy, 2019;255:113829.

[18] Khazaee M, Rezaniakolaie A, Moosavian A, Rosendahl. A novel method for autonomous remote condition monitoring of rotating machines using piezoelectric evergy harvesting approach. Sensors and Actuators A: Physical, 2019;295:37-50.

[19] Caliò R, Rongala U, Camboni D, Milazzo M, Stefanini C, de Petris G, Oddo C. Piezoelectric energy harvesting solutions. Sensors, 2014;14(3):4755-4790.

[20] Kim H, Tadesse Y, Priya S. Piezoelectric energy harvesting. In: Priya S, Inman DJ, editors. Energy Harvesting Technologies, US: Springer, 2009, p. 3-39.

[21] Jiang Y, Shiono S, Hamada H, Fujita T, Higuchi K, Maenaka K. Low-frequency energy harvesting using a laminated PVDF cantilever with a magnetic mass. In: Proceedings of PowerMEMS, Leuven, Belgium, pp. 375-378;2010.

[22] Cha Y, Hong J, Lee J, Park JM, Kim K. Flexible piezoelectric energy harvesting from mouse click motions. Sensors, 2016;16(7):1045.

[23] Yang Z, Zhu J. Comparison of PZN-PT, PMN-PT single crystals and PZT ceramic for vibration energy harvesting. Energy Conversion and Management, 2016;122: 321-329.

[24] Kim C, Shin JW. Topology optimisation of piezoelectric materials and application to the cantilever beams for vibration energy harvesting. International Journal of Precision Engineering and Manufacturing, 2013;14(11):1925-1931.

[25] Luo J, Hackenberger W, Zhang S, Shrout TR. Elastic, piezoelectric and dielectric properties of PIN-PMN-PT crystals grown by Bridgman method. In: IEEE Ultrasonics Symposium, Beijing, pp. 261-264;2008.

[26] Zhang S, Li F, Sherlock NP, Luo J, Lee HJ, Xia R, Meyer RJ, Hackenberger W, Shrout TR. Recent developments on high Curie temperature PIN-PMN-PT ferroelectric crystals. Journal of Crystal Growth, 2011;318(1):846-850.

[27] DeAngelis DA, Schulze GW. Performance of PIN-PMN-PT single crystal piezoelectric versus PZT8 piezoceramic materials in ultrasonic transducers. Physics Procedia, 2015;63:21-27. 
[28] Berlincourt D, Krueger HHA, Near C. Properties of morgan electro ceramics. Technical Publication TP-226, Morgan-Electroceramics, Retrieved from http://www.ultrasonic-resonators.org/misc/references/articles/Berlincourt_'Prop erties_of_Morgan_Electro_Ceramic_Ceramics'_(Morgan_Technical_Publication_ TP-226).pdf; 28 April, 2016.

[29] Berlincourt D, Piezoelectric Crystals and Ceramics. In: Mattiat O.E. (eds) Ultrasonic Transducer Materials. Ultrasonic Technology (A Series of Monographs). Springer, Boston, MA, 1971, p102-106.

[30] June WH, Jung KY, Bae KG. Ferroelectric properties of bismuth-doped PMT-PT ceramics. Journal of the Korean Physical Society, 2010;57(6):1522-1525.

[31] Zhang S, Xia R, Shrout TR. Modified $\left(\mathrm{K}_{0.5} \mathrm{Na}_{0.5}\right) \mathrm{NbO}_{3}$ based lead-free piezoelectrics with broad temperature usage range. Applied Physics Letters, 2007; 91(13): 132913.

[32] Zhang S, Lee HJ, Shrout TR. NBT based lead-free piezoelectric materials for high power applications. U.S. Patent 20100133461. June 3, 2010.

[33] Shrout TR, Zhang S. Lead-free piezoelectric ceramics: Alternatives for PZT?. Journal of Electroceramics, 2007;19(1):111-124.

[34] Polyvinylidene Fluoride material information. GoodFellow. Retrieved from http://www.goodfellow.com/E/Polyvinylidenefluoride.html

[35] PVDF properties and uses. Precision Acoustics. Retrieved from https://www. acoustics.co.uk/pal/wp-content/uploads/2015/11/Properties-of-poled-PVDF.pdf; November, 2015.

[36] Deraemaeker A, Nasser H. Numerical evaluation of the equivalent properties of Macro Fiber Composite (MFC) transducers using periodic homogenization. International Journal of Solids and Structures, 2010;47(24):3272-3285.

[37] Bomlai P, Muensit N, Milne SJ. Structural and electrical properties of (1-x) (Na0.465K0.465 Li0.07)NbO3 - x CaTiO3 lead-free piezoelectric ceramics with high Curie temperature. Procedia Engineering, 2012;32:814-820.

[38] Ashok K, Mamatha B, Sarah P. Electrical properties of lead free Sr0.8Na0.1Sm0.1Bi4Ti4O15 ceramics. Procedia Materials Science, 2015;10:542547.

[39] Ditas P, Henning E, Kynast A. Lead-free piezoceramic materials for ultrasonic applications. In: Sensors and Measuring Systems 2014; 17. ITG/GMA Symposium, Nuremberg, Germany, pp. 1-4;2014.

[40] Hennig E, Kynast A. Lead-free piezoceramic materials for industrial applications. In: 42 ${ }^{\text {nd }}$ Annual UIA Symposium, Orlando; April 2013.

[41] Rho JH, Ahn JH, Lee NE, Ahn JH. Mechanically flexible PZT thin films on plastic substrates. In: $3^{\text {rd }}$ International Nanoelectronics Conference, Hong Kong, pp. 246247;2010.

[42] Pan CT, Liu ZH, Chen YC, Chang WT, Chen YJ. Study of vibration-induced broadband flexible piezoelectric $\mathrm{ZnO}$ micro-harvester with storage system. In: $16^{\text {th }}$ International Solid-State Sensors, Actuators and Microsystems Conference, Beijing, pp. 1669-1672;2011.

[43] Park KI, Son JH, Hwang GT, Jeong CK, Ryu J, Koo M, Choi I, Lee SH, Byun M, Wang ZL, Lee KJ. Highly-efficient, flexible piezoelectric PZT thin film nanogenerator on plastic substrates. Advanced Materials, 2014;26(16):2514-2520.

[44] Seveno R, Guiffard B, Dufay T, Thomas JC. Flexible PZT/Aluminium thin films characterizations for energy harvesting at very low frequencies $(\sim 1 \mathrm{~Hz})$. In: Joint IEEE International Symposium on the Applications of Ferroelectric, International 
Symposium on Integrated Functionalities, and Piezoelectric Force Microscopy Workshop, Singapore, pp. 94-97;2015.

[45] Qi Y, Jafferis NT, Lyons Jr. K, Lee CM, Ahmad H, McAlpine MC. Piezoelectric ribbons printed onto rubber for flexible energy conversion. Nano Letters, 2010; 10(2):524-528.

[46] Muhamad L, Salleh H. Enhancement of piezoelectric energy harvester power density using natural rubber. In: IEEE 2nd International Symposium on Telecommunication Technologies, Langkawi, pp. 51-55;2014.

[47] Resali MSM, Salleh H. Effect of rubber compound treatment and PTFE extension beam on piezoelectric energy harvester power density. Journal of Mechanical Engineering, 2017;2(2);199-214.

[48] Energy-generating rubber combines flexibilities and high-output. Ricoh. Retrieved from https://www.ricoh.com/release/2015/0518_1.html; 18 May, 2015.

[49] Mineto AT, Pereira M, Braun DS, Harvesting E. Modelling of a cantilever beam for piezoelectric energy harvesting. In: Proceedings of the $9^{\text {th }}$ Brazilian Conference on Dynamics Control and Their Applications, Serra Negra, pp. 599-605;2010.

[50] Roundy S, Leland ES, Baker J, Carleton E, Reilly E, Lai E, Otis B, Rabaey JM, Sundararajan V, Wright PK. Improving power output for vibration-based energy scavengers. IEEE Pervasive Computing, 2005;4(1):28-36.

[51] Ben Ayed S, Najar F, Abdelkefi A. Shape improvement for piezoelectric energy harvesting applications,. In: 3rd International Conference on Signals, Circuits ad Systems, Medenine, pp. 1-6;2009.

[52] Shebeeb A, Salleh H. Effect of cantilever shape on the power output of a piezoelectric bimorph generator. In: IEEE International Conference on Semiconductor Electronics, Melaka, pp. 275-278;2010.

[53] Muthalif AGA, Nordin NHD. Optimal piezoelectric beam shape for single and broadband vibration energy harvesting: Modeling, simulation and experimental results. Mechanical System and Signal Processing, 2014;54:417-426.

[54] Salim M, Salleh H, Loh EWK, Khir M, Salim D. New simulation approach for tuneable trapezoidal and rectangular piezoelectric bimorph energy harvesters. Microsystem Technologies, 2017;23(6),2097-2106.

[55] Basari AA, Awaji S, Wang S, Hashimoto S, Kumagai S, Suto K, Okada H, Okuno H, Homma B, Jiang W, Wang S. Shape effect of piezoelectric energy harvester on vibration power generation. Journal of Power and Energy Engineering, 2014;2:117124.

[56] Benasciutti D, Moro L, Zelenika S, Brusa E. Vibration energy scavenging via piezoelectric bimorphs of optimised shapes. Microsystem Technology, 2010;16(5): 657-668.

[57] Hosseini R, Hamedi M. An investigation into resonant frequency of trapezoidal $\mathrm{V}$ - shaped cantilever piezoelectric energy harvester. Microsystem Technologies, 2015;22(5):1127-1134.

[58] Kherbeet ASh, Salleh H, Salman BH, Salim M. Vibration-based piezoelectric micropower generator for power plant wireless monitoring application. Sustainable Energy Technologies and Assessments, 2015;11:42-52.

[59] Siddiqui NA, Kim SB, Kim DJ, Overfelt R, Prorok B. Shape optimisation of cantilevered piezoelectric devices. In: Shaw III G, Prorok B, Starman L, Furlong C, editors. MEMS and Nanotechnology, Volume 5. Conference Proceedings of the Society for Experimental Mechanical Series. Springer Cham, 2014; p 43-48. 
[60] Su H, Sui L, Song P, Lu Y. Theoretical analysis and experimental study of a perforated piezoelectric cantilever. IOP Conference Series: Materials Science and Engineering, 2019;563:032039.

[61] Reddy AR, Umapathy M, Ezhilarasi D, Uma G. Cantilever beam with trapezoidal cavity for improved energy harvesting. International Journal of Precision and Engineering Manufacturing, 2015;16(8):1875-1881.

[52] Mehdipour I, Braghin F. Innovative piezoelectric cantilever beam shape for improved energy harvesting. In: Wicks A, editor. Shock \& Vibration, Aircraft/Aerospace, and Energy Harvesting, Volume 9. Conference Proceedings of the Society for Experimental Mechanical Series. Springer Cham, 2015, p 19-24.

[63] Song HC, Kim HC, Kang CY, Kim HJ, Yoon SJ, Jeong DY. Multilayer piezoelectric energy scavenger for large current generation. Journal of Electroceramics, 2009;23: 301-304.

[64] Zhu D, Almusallam A, Beeby S, Tudor J, Harris N. A bimorph multi-layer piezoelectric vibration energy harvester. In: Proceedings of PowerMEMS, Leuven, Belgium, pp 335-338;2010.

[65] Zhu D, Beeby S, Tudor J, White N, Harris N. Improving output power of piezoelectric energy harvesters using multilayer structures. Procedia Engineering, 2011;25:199-202.

[66] Jemai A, Najar F, Chafra M. Parametric analysis of multilayered unimorph piezoelectric vibration energy harvesters. Journal of Vibration and Control, 2015; 23(16):2538-2553.

[67] Shin DJ, Jeong SJ, Seo CE, Cho KH, Koh JH. Multi-layered piezoelectric energy harvesters based on PZT ceramic actuators. Ceramics International, 2015;41:686690.

[68] Lam MH, Salleh H. PZT piezoelectric energy harvester enhancement using slotted aluminium beam. Advanced Materials Research, 2014;1051:932-936.

[69] Salleh H, Lam MH, Muhamad L, Jaafar MF. Structural modification strategies to improve piezoelectric energy harvester performance. Applied Mechanics and Materials, 2015;752-753:934-940.

[70] Hong SK, Yang CH, Jabbar H, Wo MS, Song D, Sung TH. Design of piezoelectric energy harvester with additional springs for varying stiffness of module. Journal of Electroceramics, 2015;35(1-4):11-18.

[71] Erturk A, Renno JM, Inman DJ. Modeling of piezoelectric energy harvesting from an L-shaped beam-mass structure with an application to UAVs. Journal of Intelligent Material Systems and Structures, 2009;20(5):529-544.

[72] Xu JW, Shao WW, Kong FR, Feng ZH. Right-angle piezoelectric cantilever with improved energy harvesting efficiency. Applied Physics Letters, 2010;96(15): 152904.

[73] Nie X, Tan T, Yan Z, Yan Z, Hajj MR. Broadband and high-efficient L-shaped piezoelectric energy harvester based on internal resonance. International Journal of Mechanical Sciences, 2019;159:287-305.

[74] Wang H, Shan X, Xie T. An energy harvester combining a piezoelectric cantilever and a single degree of freedom elastic system. Journal of Zhejiang University Science A, 2012;13(7):526-537.

[75] Staaf LGH, Köhler E, Parthasarathy D, Lundgren P, Enoksson P. Simulation and experimental demonstration of improved efficiency in coupled piezoelectric cantilevers by extended strain distribution. Sensors Actuators A: Physical, 2015;229: 136-140. 
[76] Malkin MC, Davis CL. Multi-frequency piezoelectric energy harvester. US Patent 2004/0075363 A1, Apr. 22, 2004.

[77] Malkin MC, Davis CL. Multi-frequency piezoelectric energy harvester. US Patent 6858970 b2, Feb. 22, 2005.

[78] Lee SK, Kim MK. Piezoelectric energy harvesting array and method of manufacturing the same. US Patent 9294015 B2, Mar. 22, 2016.

[79] Xue H, Hu Y, Wang QM. Broadband piezoelectric energy harvesting devices using multiple bimorphs with different operating frequencies. IEEE Transactions of Ultrasonics, Ferroelectrics and Frequency Control, 2008;55(9).

[80] Zhang H, Afzalul K. Design and analysis of a connected broadband multipiezoelectric bimorph-beam energy harvester. IEEE Transactions on Ultrasonics, Ferroelectrics and Frequency Control, 2014;61(1):1016-1023.

[81] Dayou J, Liew WYH, Chow MS. Increasing the bandwidth of the width-split piezoelectric energy harvester. Microelectronics Journal, 2012;43(7):484-491.

[82] Chow MS, Dayou J, Liew WYH. Increasing the output from piezoelectric energy harvester using width-split method with verification International Journal of Precision Engineering and Manufacturing, 2013;14(12):2149-2155.

[83] Liu Z, Lia L. Modeling of energy harvesting device with segmented piezoelectric layer. Procedia Engineering, 2010;47:470-473.

[84] De Marqui Jr. C, Erturk A, Inman DJ. Effect of segmented electrodes on piezoelastic and piezo-aero-elastic responses of generator plates. In: ASME Smart Materials, Adaptive Structures and Intelligent Systems, Volume 1: Active Materials, Mechanics and Behavior; Modeling, Simulation and Control, Oxnard, California, pp 111-122;2009.

[85] Zizys D, Gaidys R, Dauksevicius R, Ostasevicius V, Daniulaitis V. Segmentation of a vibro-shock cantilever-type piezoelectric energy harvester operating in higher transverse vibration modes. Sensors, 2016;16(1):11.

[86] Lee S, Youn BD, Giraud M. Designing energy harvesting skin structure utilising outdoor unit vibration. In: ASME International Design Engineering Technical Conference \& Computers and Information in Engineering Conference, Montreal, Canada, pp 713-723;2010.

[87] Youn BD, Yoon H, Jung B, Kim YY. Piezoelectric energy harvesting skin and its application to self-powered wireless sensor network. In: Mescia L, Losito O, Prudenzano F, editors. Innovative Materials and Systems for Energy Harvesting Applications. Hershey PA: Engineering Science Reference, 2015, p 93-115.

[88] Lee S, Youn BD. A new energy harvesting design concept: Energy harvesting skin. In: 13h AIAA/ISSMO Multidisciplinary Analysis Optimisation Conference, Fort Worth, Texas;2010.

[89] Lee S, Youn BD. A new energy harvesting design concept: Multimodal energy harvesting skin. IEEE Transactions on Ultrasonics, Ferroelectrics and Frequency Control, 2011;58(3):629-645.

[90] Tang L, Yang Y, Soh CK. Broadband vibration energy harvesting techniques. In: Elvin N, Erturk A, editors. Advances in Energy Harvesting Methods, New York: Springer, 2013, p 17-61.

[91] Ferrari M, Baù M, Cerini F, Ferrari V. Impact-enhanced multi-beam piezoelectric converter for energy harvesting in autonomous sensors. Procedia Engineering, 2012;47:418-421. 
[92] Dauksevicius R, Briand D, Lockhart R, Quintero AV, de Rooij N, Gaidys R, Ostasevicius V. Frequency up-converting vibration energy harvester with multiple impacting beams for enhanced wideband operation at low frequencies. Procedia Engineering, 2014;87:1517-1520.

[93] Vijayan K, Friswell MI, Khodaparast H, Adhikari S. Non-linear energy harvesting from coupled impacting beams. International Journal of Mechanical Sciences, 2015; 96-97:101-109.

[94] Shih YS, Vasic D, Costa F, Wu WJ. Magnetic stoppers on single beam piezoelectric energy harvesting. Physics Procedia, 2015;70:1022-1026.

[95] Liu S, Cheng Q, Zhao D, Feng L, Theoretical modeling and analysis of two-degreeof-freedom piezoelectric energy harvester with stopper. Sensors and Actuators A: Physical, 2016;245:97-105.

[96] Maeguchi T, Masuda A, Katsumura H, Kagata H, Okumura H. Band widening of piezoelectric vibration energy harvesters by utilising mechanical stoppers and magnets. Journal of Physics: Conference Series, 2015;660.

[97] Jiang WA, Chen LQ. Energy harvesting of monostable duffing oscillator under gaussian white noise excitation. Mechanics Research Communications, 2013;53:85-91.

[98] Daqaq MF. Response of uni-modal duffing-type harvesters to random forced excitations. Journal of Sound and Vibration, 2010;329:3621-3631.

[99] Ramlan R, Brennan MJ, Mace R. Nonlinear bistable mechanism for energy harvesting device. In: $7^{\text {th }}$ European Conference on Structural Dynamics Proceedings of EURODYN, University of Southampton, pp 12;2008.

[100] Ramlan R, Brennan MJ, Mace BR, Kovacic I. Potential benefits of a non-linear stiffness in an energy harvesting device. Nonlinear Dynamics. 2010;59(4):545-558.

[101] Cottone F, Vocca H, Gammaitoni L. Nonlinear energy harvesting. Physical Review Letters, 2009;102(8):080601.

[102] Li XY, Shen YD, Pan XM, Li ZZ, Cheng TH, Huang X, Chen X, Chen YL. Piezoelectric material based energy generator using bistable cantilever beam. Future Wireless Networks and Information Systems, 2012;143:517-522.

[103] Pellegrini SP, Tolou N, Schenk M, Herder JL. Bistable vibration energy harversters: A review. Journal of Intelligent Material Systems and Structures, 2012;24(11):1303-1312.

[104] Daqaq MF, Masana R, Erturk A, Quinn DD. On the role of nonlinearities in vibratory energy harvesting: A critical review and discussion. ASME Applied Mechanics Reviews, 2014;66(4).

[105] Andó B, Baglio S, Maiorca F, Trigona C. Two dimensional bistable vibration energy harvester. Procedia Engineering, 2012 47:1061-1064.

[106] Andó B, Baglio S, Latorre L, Maiorca F, Nouet P, Trigona C. Magnetically-coupled cantilevers with antiphase bistable behavior for kinetic energy harvesting. Procedia Engineering, 2012;47:1065-1068.

[107] Lin JT, Lee B, Alphenaar B. The magnetic coupling of a piezoelectric cantilever for enhanced energy harvesting efficiency. Smart Materials and Structures, 2010;19(4).

[108] Yang J, Wen Y, Li P, Bai X, Li M. Improved piezoelectric multifrequency energy harvesting by magnetic coupling. In: IEEE SENSORS Proceedings, Limerick, pp 28-31;2011.

[109] Zhou S, Cao J, Erturk A, Lin J. Enhanced broadband piezoelectric energy harvesting using rotatable magnets. Applied Physics Letters, 2013;102. 
[110] Wu X, Lee DW. Magnetic coupling between folded cantilevers for high-efficiency broadband energy harvesting. Sensors and Actuators A: Physical, 2015;234:17-22.

[111] Zhou S, Cao J, Inman DJ, Lin J, Liu S, Wang Z. Broadband tristable energy harvester: modeling and experiment verification. Applied Energy, 2014;133:33-39.

[112] Zhou S, Chao J, Wang Z. Exploitation of a tristable nonlinear oscillator for improving broadband vibration energy harvesting. The European Physical Journal - Applied Physics, 2014:67(3).

[113] Panyam M, Daqaq MF. Characterizing the effective bandwidth of tri-stable energy harvesters. Journal of Sound and Vibration,2017;386:336-358.

[114] Zhou Z, Qin W, Zhu P. Improved efficiency of harvesting random energy by snapthrough in a quad-stable harvester. Sensors and Actuators A: Physical, 2016;243: 151-158.

[115] Zhou Z, Qin W, Zhu P. A broadband quad-stable energy harvester and its advantages over bi-stable harvester: Simulation and experiment verification. Mechanical Systems and Signal Processing, 2017;84(A):158-168.

[116] Wang C, Zhang Q, Wang W. Low-frequency wideband vibration energy harvesting by using frequency up-conversion and quin-stable nonlinearity. Journal of Sound and Vibration, 2017;399:169-182.

[117] Wang H, Tang L. Modeling and experiment of bistable two-degree-of-freedom energy harvester with magnetic coupling. Mechanical Systems and Signal Processing, 2017;86:29-39.

[118] Green PL, Papatheou E, Sims ND. Energy harvesting from human motion and bridge vibrations: An evaluation of current nonlinear energy harvesting solutions. Journal of Intelligent Material Systems and Structures, 2013;24(12):1494-1505.

[119] Challa VR, Prasad MG, Fisher FT. A coupled piezoelectric-electromagnetic energy harvesting technique for achieving increased power output through damping matching. Smart Matererials and Structures, 2009;18(9):095029.

[120] Lallart M, Inman DJ. Mechanical effect of combined piezoelectric and electromagnetic energy harvesting. In: Proulx T, editor. Structural dynamics and renewable energy vol. 1, New York: Springer, 2011, p 261-272.

[121] Wang H, Tang L, Guo Y, Shan X, Xie T. A 2dof hybrid energy harvester based on combined piezoelectric and electromagnetic conversion mechanisms. Journal of Zheijiang University Science A, 2014;15(9):711-722.

[122] Resali MSM, Salleh H. Wireless condition monitoring system for rotating machinery powered by a hybrid vibration based energy harvester. Journal of Mechanical Engineering, 2017;4(2):249-267.

[123] Shan XB, Guan S, Liu Z, Xu Z, Xie T. A new energy harvester using a piezoelectric and suspension electromagnetic mechanism. Journal of Zheijiang University Science A, 2013:14(12):890-897.

[124] Xu Z, Shan X, Chen D, Xie T. A novel tunable multi-frequency hybrid vibration energy harvester using piezoelectric and electromagnetic conversion mechanisms. Applied Science, 2016;6(1):10.

[125] Xu Z, Yang H, Zhang H, Ci H, Zhou M, Wang W, Meng A. Design and analysis of a magnetically coupled multi-frequency hybrid energy harvester. Sensors. 2019;14:3203.

[126] Li P, Gao S, Cai H, Wu L. Theoretical analysis and experimental study for nonlinear hybrid piezoelectric and electromagnetic energy harvester. Microsystem Technologies, 2016;22:727-739. 
[127] Elfrink R, Pop V, Hohlfeld D, Kamel TM, Matova S, de Nooijer C, Jambunathan M, Goedbloed M, Caballero L, Renaud M, Penders J, van Schaijk R. First autonomous wireless sensor node powered by a vacuum-packaged piezoelectric MEMS energy harvester. In: IEEE International Electron Devices Meeting (IEDM), Baltimore, MD, pp 1-4;2009.

[128] Kwon DS, Ko HJ, Kim J. Piezoelectric and electromagnetic hybrid energy harvester using two cantilevers for frequency up-conversion. In: IEEE $30^{\text {th }}$ International Conference on Micro Electro Mechanical Systems (MEMS), Las Vegas, NV, pp. 49-52;2017.

[129] Edwards B, Aw KC, Hu AP, Tang L. Hybrid electromagnetic-piezoelectric transduction for a frequency up-converted energy harvester. In: IEEE Internal Conference on Advanced Intelligent Mechatronics, Busan, pp. 1149-1154;2015.

[130] Chen R, Ren L, Xia H, Yuan X, Liu X. Energy harvesting performance of a dandelion-like multi-directional piezoelectric vibration energy harvester. Sensors Actuators A Physical, 2015;230:1-8.

[131] Yang Z, Zu J. A novel multi-directional nonlinear piezoelectric energy harvester coupled with nonlinear conditioning circuits. In: ASME International Design Engineering Technical Conference \& Computers and Information in Engineering Conference, Volume 8: 27th Conference on Mechanical Vibration and Noise, Boston, Massachusetts; 2-5 August 2015.

[132] Yang Z, Zu J. Multi-directional high efficiency piezoelectric energy transducer. US Patent 2015/0358737 A1, Dec. 10, 2015.

[133] Park JC, Park JY. Asymmetric PZT bimorph cantilever for multi-dimensional ambient vibration harvesting. Ceramics International, 2013;39:8653-8657.

[134] Wang K, Hu F, Mau M, Liu Y, Wang H. Design of a multi-directional piezoelectric energy harvester with spring and magnetic coupling. In: IEEE International Conference on Power and Renewable Energy (ICPRE), Shanghai, pp 126$129 ; 2016$.

[135] Ceponis A, Mazeika D, Kilikevicius. Bidirectional piezoelectric energy harvester. Sensor, 2019;19(18):3845. 